\title{
Prevalence and predictors of hepatitis $B$ virus (HBV) infection in east Africa: evidence from a systematic review and meta-analysis of epidemiological studies published from 2005 to 2020
}

\author{
Hussein Mukasa Kafeero ${ }^{1,2^{*}}$, Dorothy Ndagire ${ }^{3}$, Ponsiano Ocama ${ }^{4}$, Ali Kudamba ${ }^{5}$, Abdul Walusansa ${ }^{1}$ and
} Hakim Sendagire ${ }^{1,2}$

\begin{abstract}
Background: The epidemiology of hepatitis B virus (HBV) in the general population in east Africa is not well documented. In this meta-analysis, we examined 37 full published research articles to synthesise up-to-date data on the prevalence and predictors of the HBV burden for the effective prevention and management of the virus in our region.

Methods: We examined 37 full published research articles found using PubMed, Scopus, African Journal Online (AJOL), and Google Scholar between May and October 2020. Dichotomous data on HBV prevalence and predictors of infection were extracted from the individual studies. The HBV prevalence, test of proportion, relative risk, and $\mathrm{I}^{2}$ statistics for heterogeneity were calculated using MedCalc software version 19.1.3. Begg's tests was used to test for publication bias. Sources of heterogeneity were analysed through sensitivity analysis, meta-regression, and subgroup analysis at $95 \% \mathrm{Cl}$. $P<0.05$ was considered significant for all analyses.

Results: The prevalence of HBV was generally high (6.025\%), with publications from Kenya (8.54\%), Uganda (8.454\%) and those from between 2011 and $2015(8.759 \%)$ reporting the highest prevalence $(P<0.05)$. Blood transfusion, scarification, promiscuity, HIV seropositivity, and being male were independent predictors significantly associated with HBV infection $(P<0.05)$, with the male sex being the most strongly associated predictor of HBV infection. Meta-regressions for the pooled HBV prevalence and sample size, as well as the year of publication, lacked statistical significance $(P>0.05)$. Omitting the study with the largest sample size slightly increased pooled HBV prevalence to $6.149 \%$, suggesting that the studies are robust. Begg's test showed no evidence of publication bias for overall meta-analysis ( $p>0.05)$.
\end{abstract}

\footnotetext{
*Correspondence: husseinmukasakafeero@gmail.com

'Department of Medical Microbiology, Faculty of Health Sciences, Habib

Medical School, Islamic University in Uganda, P.O. Box 7689, Kampala,

Uganda

2Department of Medical Microbiology, College of Health Sciences, Makerere University, P.O. Box 7062, Kampala, Uganda

Full list of author information is available at the end of the article
}

C C The Author(s). 2021 Open Access This article is licensed under a Creative Commons Attribution 4.0 International License, which permits use, sharing, adaptation, distribution and reproduction in any medium or format, as long as you give appropriate credit to the original author(s) and the source, provide a link to the Creative Commons licence, and indicate if changes were made. The images or other third party material in this article are included in the article's Creative Commons licence, unless indicated otherwise in a credit line to the material. If material is not included in the article's Creative Commons licence and your intended use is not permitted by statutory regulation or exceeds the permitted use, you will need to obtain permission directly from the copyright holder. To view a copy of this licence, visit http://creativecommons.org/licenses/by/4.0/. The Creative Commons Public Domain Dedication waiver (http://creativecommons.org/publicdomain/zero/1.0/) applies to the data made available in this article, unless otherwise stated in a credit line to the data. 
Conclusion: The burden of HBV is still high, with the male sex, blood transfusion, body scarification, and HIV seropositivity being potential predictors of infection. Thus, it is important to scale up control and prevention measures targeting persons at high risk.

Keywords: East Africa, Hepatitis B, Prevalence, HBsAg, Predictors

\section{Background}

Hepatitis B virus (HBV) is one of the key etiological agents for liver diseases, including chronic hepatitis, liver cirrhosis, and liver cancer [1]. It is the second commonest human carcinogen after tobacco [2]. The virus is highly contagious and is 50 to 100 times more infectious than the human immunodeficiency virus (HIV). Its extreme resilience allows it to survive for more than a week on dry surfaces, complicating its epidemiology and increasing the risk of horizontal intra-familial transmission [3]. According to the World Health Organization (WHO), countries of Africa, Asia, and South America have carrier rates as high as $8 \%$, with sub-Saharan Africa accounting for $20 \%$ of the global burden [4]. This implies an unmet need in the control and management of the pandemic in Africa. Furthermore, although a highly effective HBV vaccine is available, immunisation among adult populations in sub-Saharan African countries is neither free nor universal [5-8].

In east Africa, data on the seroprevalence of HBV are isolated and confined to only sub-group studies including, but not limited to, studies of blood donors [9], health care workers [10], pregnant women on antenatal care [11, 12], as well as HIV-positive cohorts [13]. Studies that examine HBV prevalence at national and regional revels are scant in the literature. This means that the risk factors to HBV infection have not been comprehensively evaluated because specific groups may present with unique predictors of infection. Therefore, understanding the epidemiology of HBV on a wide regional scale would not only offer evidence-based data on HBV prevalence but also provide an array of the putative risk factors associated with HBV infection at a regional level.

The risk factors of HBV infection depend largely on beliefs and cultural practices, both of which vary from one community to another [14]. Several primary studies elsewhere have highlighted the key risk factors associated with $\mathrm{HBsAg}$ seropositivity, including history of blood transfusion, low level of education, surgery, sexually transmitted infections, abortions, higher mean parity, engaging in early sexual activities, polygamy, being male, having a rural birthplace, and engaging in sex with multiple partners [15-19]. However, Lawal et al. [20] did not observe a significant association between HBV infection and the sharing of a toothbrush, the sharing of needles, incision marks/tattoos, hepatitis B immunisation status, history of blood transfusion, previous surgical operations, sexual exposure/abuse, history of jaundice, or genital circumcision. Thus, because of these inconsistent findings in the literature about which risk factors are more significant for community infections with HBV, our systematic review and meta-analysis aimed to find the key putative predictors associated with the high HBV prevalence in East Africa. This could significantly contribute towards the achievement of the ambitious sustainable development goal of eliminating hepatitis B virus (HBV) infections by 2030 [21]. To the best of our knowledge, this is the first study to give a detailed analysis of the status of HBV infection in our region. The overall pooled prevalence in the region, the sub-group pooled prevalence, and the associated risk factors could be valuable for designing and implementing public health measures to reduce the burden of HBV infection in east Africa.

\section{Materials and methods}

\section{Systematic review protocol registration, information} sources, and search strategies

Our study was designed to investigate the prevalence and predictors of hepatitis B virus infection in east Africa. We registered the protocol with the International Prospective Register of Systematic Reviews (PROSPERO), University of York Centre for Reviews and Dissemination (https://www.crd.york.ac.uk/PROSPERO), under the registration number CRD42021251974. The findings of the review were reported based on the Preferred Reporting Items for Systematic Review and MetaAnalysis (PRISMA) 2020 statement checklist [22]. We searched the following electronic databases; PubMed, Scopus, African Journals Online (AJOL), and Google Scholar for studies published from 2005 to 2020 that investigated the prevalence and predictors of HBV infection in east Africa.

A thorough review of the titles, abstracts, and full papers was done by three reviewers (HMK, AW, and AK). Any disagreement between the three was settled by consensus during weekly evaluation meetings. A full-text analysis of studies that qualified, including identification of duplicated records, was conducted by HMK, AW, and AK. Only the full-text articles were retained for data extraction.

The population, exposure, comparison and outcome (PECO) strategy was used throughout our search strategy. Regarding the population, all studies conducted on 
Table 1 Keywords used for searching in databases

\begin{tabular}{ll}
\hline Field searched & Key words \\
\hline HBV prevalence & $\begin{array}{l}\text { "Hepatitis B prevalence", "Hepatitis B prevalence in East Africa", "Hepatitis B prevalence in Uganda", "Hepatitis B prevalence in } \\
\text { Kenya", "Hepatitis B prevalence in South Sudan", "Hepatitis B prevalence in Rwanda", "Hepatitis B prevalence in Tanzania", } \\
\text { "Hepatitis B prevalence in Burundi" }\end{array}$ \\
$\begin{array}{ll}\text { Risk factors to HBV } \\
\text { infection }\end{array}$ & $\begin{array}{l}\text { HBV prevalence and "age", "Gravidity", "Marital status" "History of STIs", "History of STIs", "History of STIs", "Education level," } \\
\text { surgery," "Number of sexual partners," "Employment" "Gender" }\end{array}$ \\
\hline
\end{tabular}

the HBV infection status that used study subjects within the east African region constituting the political East African Community (EAC) member states were searched for data extraction. Pertaining to the exposure status, the number of persons exposed and unexposed to $\mathrm{HBV}$ within the sample used in the separate studies indicated the prevalence of HBV. Regarding comparison, the data on the predictors of infection were searched for from the main body of the research article and then compared among the exposed and the unexposed to HBV. Finally, concerning the outcome, the central outcome was HBV infection in the population, while the supplementary outcomes were the relative $\mathrm{HBsAg}$ seropositivity depending on the diagnostic methods used for $\mathrm{HBV}$ detection (ELISA, RDTs, EIA, and CMEA) and the predictors of HBV infection.

The search terms used are presented in Table 1. These were used either in isolation or in combination using the Boolean operators 'OR' and 'AND'. The titles and abstracts were searched for the keywords for HBV prevalence, while the full text of each article was searched for the keywords related to the associated risk factors for HBV infection. The three authors (HMK, AW, and AK) separately extracted the following data: first author, year of publication, country, sampling technique, sample size, hepatitis B surface antigen positivity ( $\mathrm{HBsAg}+)$, $\mathrm{HBsAg}$ detection methods, and quality score.

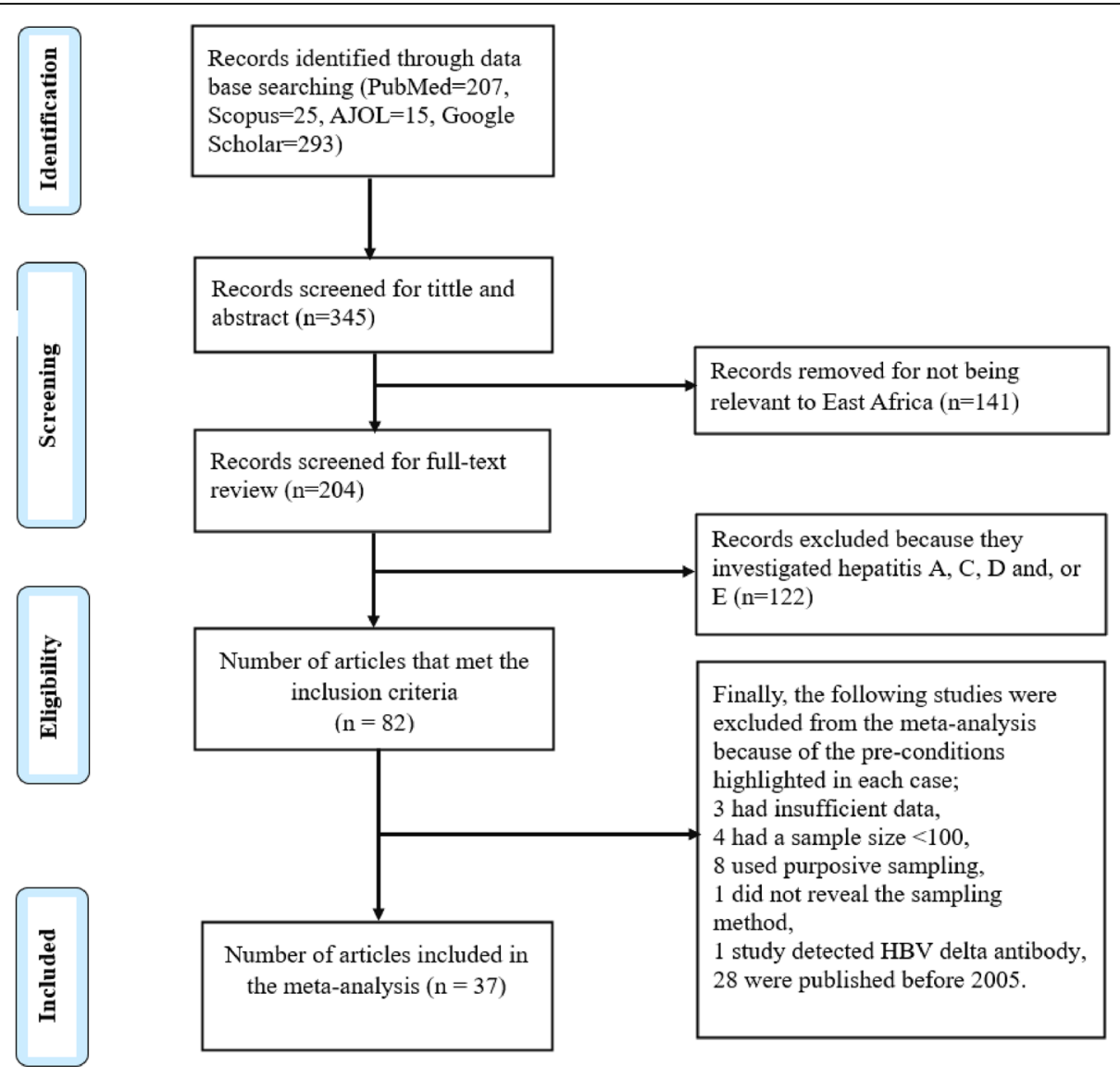

Fig. 1 Flow chart for study eligibility following PRISMA criterion; AJOL: African Journal Online, HBV: Hepatitis B Virus 
Table 2 Characteristics of the included studies in the systematic review and meta-analysis for the prevalence of hepatitis B virus in East Africa

\begin{tabular}{|c|c|c|c|c|c|c|c|}
\hline First author, Year & Year & Country & Sampling technique & Sample & HBsAg+ & Detection method & QS \\
\hline Mutagoma et al., 2017 [26] (1) & 2017 & Rwanda & Entire & 13,121 & 486 & AAS & 9 \\
\hline Hasegawa I et al., 2006 [27] (2) & 2006 & Tanzania & voluntary & 457 & 22 & CLEIA & 7 \\
\hline Twagirumugabe et al., 2017 [28] (3) & 2017 & Rwanda & Entire & 13,637 & 559 & CMIA & 8 \\
\hline Bwogi et al., 2009 [29] (4) & 2009 & Uganda & Probability & 5875 & 606 & EIA & 9 \\
\hline Kwizera R et al., 2018 [9] (5) & 2018 & Burundi & Entire & 8993 & 94 & EIA & 7 \\
\hline Matee et al., 2006 [30] (6) & 2006 & Tanzania & Entire & 1599 & 141 & EIA & 8 \\
\hline Mueller et al., 2015 [31] (7) & 2015 & Tanzania & Entire & 598 & 42 & EIA & 8 \\
\hline Bayo P, et al., 2014 [32] (8) & 2014 & Uganda & Probability & 402 & 47 & ELISA & 8 \\
\hline Bongomin P et al., 2005 [33] (9) & 2005 & Uganda & Entire & 170 & 19 & ELISA & 8 \\
\hline Harania RS et al., 2008 [34] (10) & 2008 & Kenya & Entire & 378 & 23 & ELISA & 7 \\
\hline Iradukunda et al., 2020 [35] (11) & 2020 & Rwanda & Random & 374 & 24 & ELISA & 8 \\
\hline Kirbak et al., 2017 [36] (12) & 2017 & South Sudan & Probability & 280 & 31 & ELISA & 8 \\
\hline Makuza et al., 2019 [37] (13) & 2019 & Rwanda & Probability & 327,360 & 12,865 & ELISA & 9 \\
\hline Muriuki et al., 2013 [38] (14) & 2013 & Kenya & Probability & 300 & 21 & ELISA & 7 \\
\hline Ngaira et al., 2016 [39] (15) & 2016 & Kenya & Entire & 287 & 11 & ELISA & 7 \\
\hline Pirillo et al., 2007 [40] (16) & 2007 & Uganda & Entire & 164 & 8 & ELISA & 7 \\
\hline Rachel et al., 2018 [13] (17) & 2018 & Uganda & Entire & 8042 & 359 & ELISA & 8 \\
\hline Rusine et al., 2013 [41] (18) & 2013 & Rwanda & Voluntary & 402 & 21 & ELISA & 7 \\
\hline Telatela SP et al., 2007 [42] (19) & 2007 & Tanzania & Entire & 167 & 2 & ELISA & 7 \\
\hline Umutesi et al., 2017 [43] (20) & 2017 & Rwanda & voluntary & 117,258 & 5042 & ELISA & 7 \\
\hline Ziraba et al., 2010 [44] (21) & 2010 & Uganda & Entire & 370 & 30 & ELISA & 8 \\
\hline Rashid S et al., 2014 [45] (22) & 2014 & Tanzania & Consecutive & 310 & 12 & MEIA & 7 \\
\hline Bartonjo, G et al., 2019 [46] (23) & 2019 & Kenya & Probability & 594 & 33 & RDT & 8 \\
\hline Geffert et al., 2020 [47] (24) & 2020 & Tanzania & Entire & 723 & 22 & RDT & 7 \\
\hline Hawkins C et al., 2013 [48] (25) & 2013 & Tanzania & Entire & 17,539 & 1079 & RDT & 8 \\
\hline Kamenya et al., 2017 [49] (26) & 2017 & Tanzania & Entire & 300 & 7 & RDT & 8 \\
\hline Kapinga, D. R. 2017 [50] (27) & 2017 & Tanzania & Random & 600 & 31 & RDT & 8 \\
\hline Kateera F et al., 2015 [10] (28) & 2015 & Rwanda & Entire & 371 & 11 & RDT & 8 \\
\hline Kayondo SP et al., 2019 [11] (29) & 2019 & Uganda & Probability & 340 & 10 & RDT & 8 \\
\hline Kilonzo SB et al., 2017 [51] (30) & 2017 & Tanzania & Entire & 743 & 49 & RDT & 7 \\
\hline Kerubo G et al., 2015 [52] (31) & 2015 & Kenya & voluntary & 268 & 56 & RDT & 7 \\
\hline Kerubo G et al., 2015 [52] (31) & 2015 & Kenya & voluntary & 1041 & 117 & RDT & 7 \\
\hline Mirambo MM et al.,2016 [8] (32) & 2016 & Tanzania & Entire & 211 & 8 & RDT & 8 \\
\hline Ng'wamkai et al., 2019 [53] (33) & 2019 & Tanzania & Entire & 499 & 29 & RDT & 8 \\
\hline Ochola et al., 2013 [6] (34) & 2013 & Uganda & Probability & 790 & 139 & RDT & 8 \\
\hline Shao R, et al., 2018 [54] (35) & 2018 & Tanzania & Entire & 442 & 25 & RDT & 8 \\
\hline Chiesa et al., 2020 [55] (36) & 2020 & Uganda & Probability & 950 & 75 & RDT & 8 \\
\hline
\end{tabular}

EIA Enzyme Immunoassay, ELISA Enzyme Linked Immunosorbent Assay, RDT Rapid Diagnostic Test, CMIA Chemiluminescent Micro-particles Immunoassay, MEIA Micro-particle Enzyme Immunoassay, CLEIA Chemiluminescent enzyme Immunoassay, QS Quality score, HBsAg Hepatitis B Surface Antigen

\section{Eligibility criteria and study selection}

Records were included in the systematic review and meta-analysis if they were full-text case-control or cohort study designs testing for HBsAg, conducted in EAC member states, and published in English in peer- reviewed journals between January of 2005 and October 15th, 2020. Excluded were case reports; reviews; abstracts of conferences; studies with insufficient or inaccessible data; pre-prints; studies with a sample size $<100$; studies that never described their sampling 


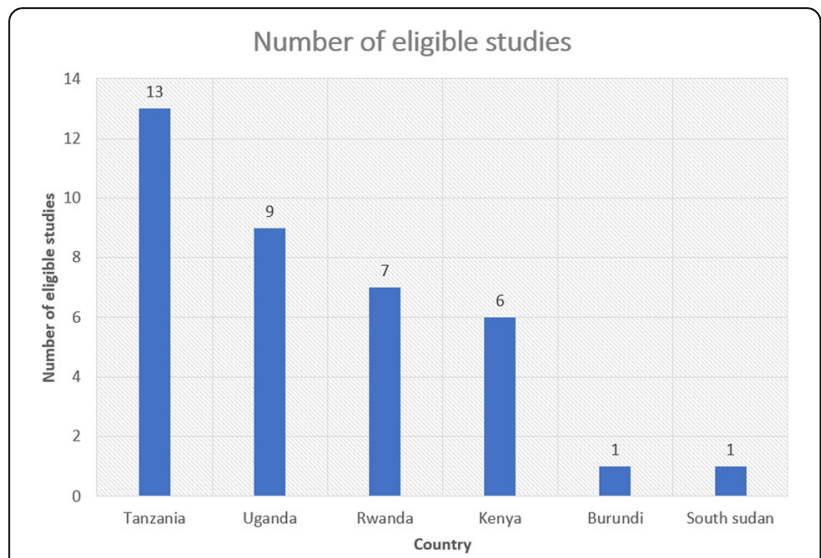

Fig. 2 Contribution of eligible studies for inclusion in the metaanalysis by country

technique or that used purposive sampling; studies that investigated other types of viral hepatitis (A, C, D, or E); studies in languages other than English; and studies published before 2005 or after November 30th, 2020.

\section{Quality assessment and data management}

For quality assessment, the Newcastle-Ottawa Scale (NOS) was used [23]. The three dimensions of selection, comparability, and exposure were considered, as described in the scale. For our meta-analysis, the selection assessed the representativeness of the sample, the sample size, the inclusion criteria, and the scope of the study.
Comparability assessed the inclusion of HBV infection risk factors and compared them among the study groups. Assessment of inclusion of exposure in the primary studies was done by looking at the outcome of the study, and a statistical tool used for the analysis (Supplementary material, S12; Table A). According to the scale, studies with scores of 9-8 were considered very high quality; 7-6, high quality; and 5-4, moderate quality. Those with scores $\leq 3$ were considered unsatisfactory and were rejected. The three reviewers (HMK, AW, and AK) independently assessed the articles for their overall methodological quality. Data from the articles or their abstracts were entered into the spreadsheet daily by all three authors (HMK, AW, and AK), who compared their separate records on a weekly basis to remove the duplicates. Each of the primary studies was evaluated by three independent hepatitis B virus experts (HMK, AK, and AW) throughout each phase of the review (screening, eligibility, and inclusion in meta-analysis). From each study, the following data were extracted: first author, year of publication, country, sampling technique, sample size, hepatitis B surface antigen positivity ( $\mathrm{HBsAg}+)$, detection method, quality score $(\mathrm{QS})$, and the predictors of HBV infection.

\section{Risk of bias in individual studies}

For the selection bias, we reviewed the data collection procedures in the primary studies (retrospective or prospective), study design (cohort, cross-sectional, or casecontrol), and recruitment strategy (from the community

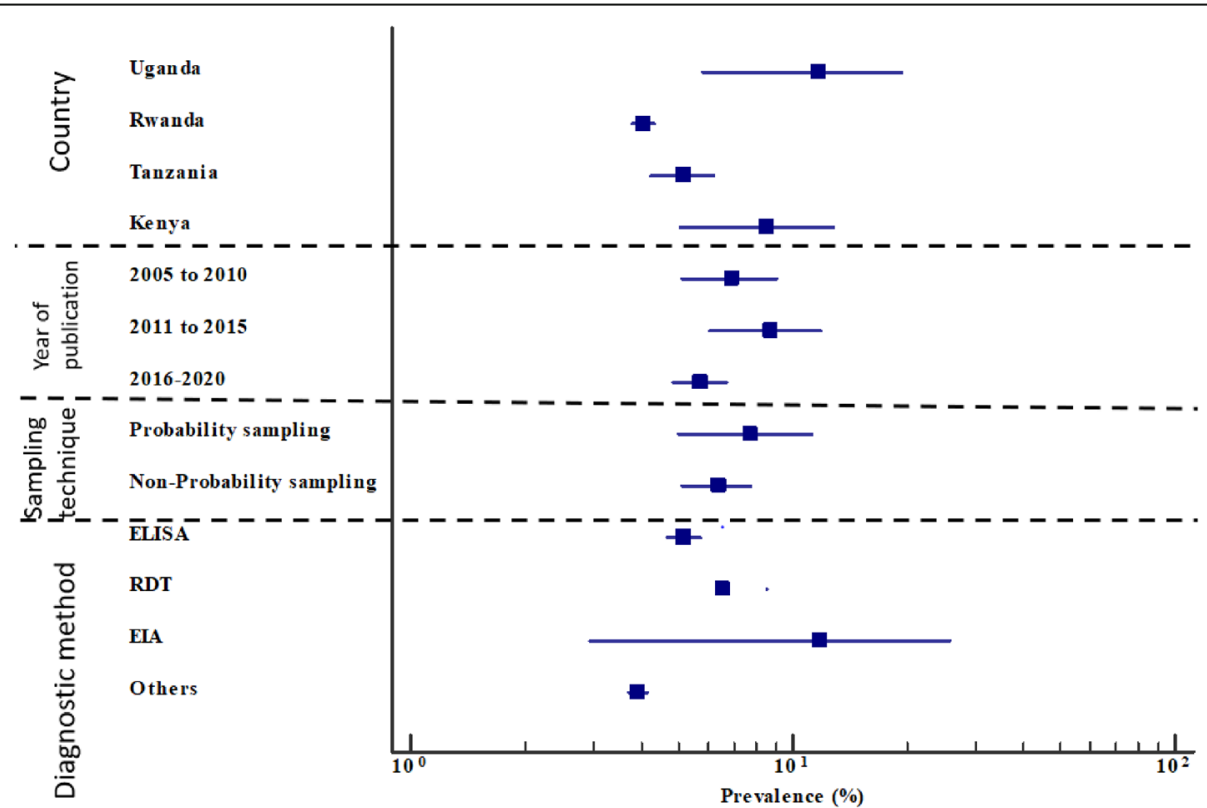

Fig. 3 Forest plot showing the HBV prevalence by country, publication period, sampling technique and HBsAg detection method; the blue diamond indicates the pooled prevalence of HBV and the horizontal line shows the $95 \%$ confidence interval. The longer the lines, the greater is the deviation from the pooled prevalence; ELISA: Enzyme Linked Immunosorbent Assay, RDT: Rapid Diagnostic Test, EIA: Enzyme Immunoassay 


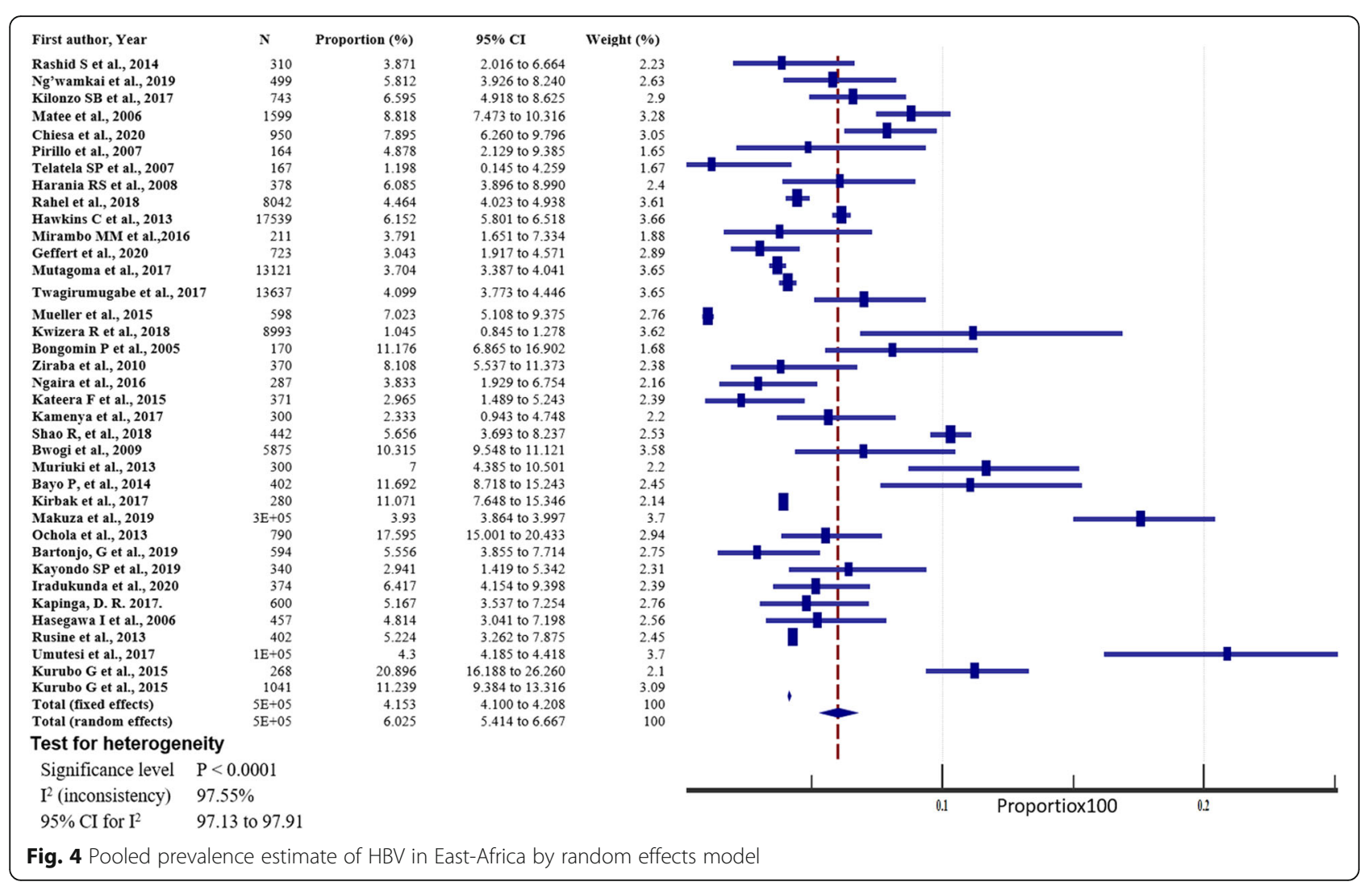

or from the hospital). For the information bias, we extracted information on methods used to determine HBV serostatus (rapid diagnostic tests, ELISA, or other immune assays). When more than one method was used to detect HBV serostatus, data were extracted using the best method used, as determined by the evaluator. All studies that used purposive sampling techniques were omitted to avoid biasing the results.

\section{Publication bias and data synthesis}

The publication bias was assessed using Begg's test, which uses Kendall's rank correlation coefficient between the meta-analysis effect size and the study weight [24]. Funnel plots were drawn for checking the existence of overall publication bias. The funnel plot asymmetry between the effect size and the meta-analysis study weight was determined by Begg's test. In this test, $P>$ 0.05 indicated no evidence of publication bias (not significant). The test $\mathrm{I}^{2}$ statistic was used to assess the heterogeneity among studies. Sources of heterogeneity were analysed through sub-group analysis, sensitivity analysis, and meta-regression. Pooled proportions, test of proportions, relative risk (RR), and the corresponding 95\% CI were used to assess the burden of HBV in the region. As a result of high heterogeneities $\left(\mathrm{I}^{2}>73 \%\right.$ and $\mathrm{P}$ het $<$ $0.05)$, the random-effects model (REM) was used to pool the HBV prevalence. However, heterogeneity was reduced for some studies that evaluated the relative risk of HBV infection, and in this case, the fixed-effects model (FEM) was used [25]. All the calculations were done using the Medcalc software version 19.1.3. The analyses of HBV prevalence, infection risk factors, and heterogeneity among studies were done at $95 \% \mathrm{CI}$, and a $p<0.05$ was considered significant. Some representative results were presented graphically using forest plots. The prevalence of HBV in each study in the forest plot is indicated by a blue square. The size of the square represents the weight contributed by each study in the meta-

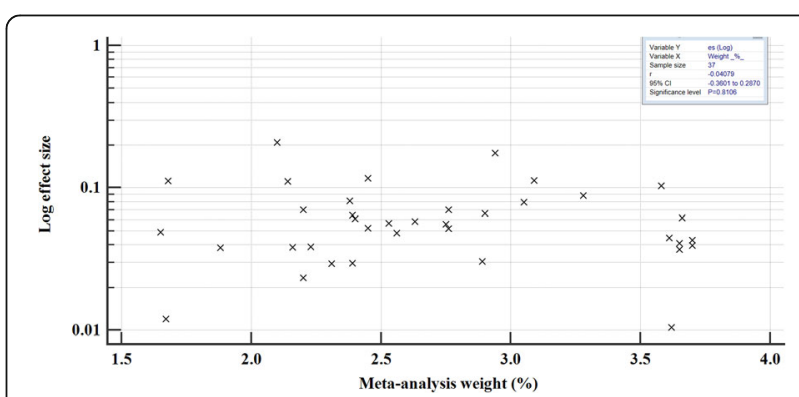

Fig. 5 Begg's correlation test for publication bias; correlation of log effect size with meta-analysis weight for all the epidemiological studies published between 2005 to 2020 included in the meta-analysis 


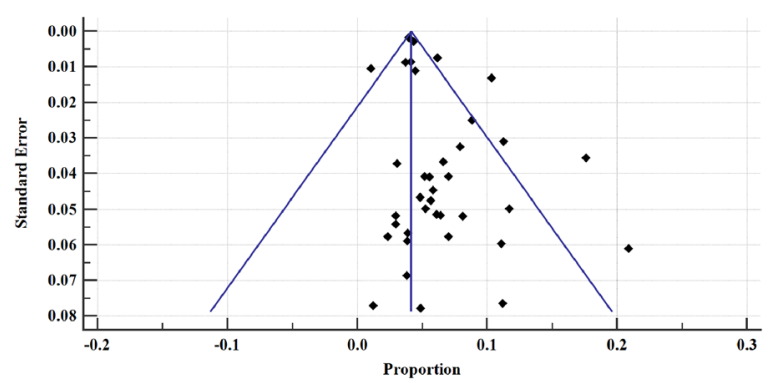

Fig. 6 Bias assessment plot of studies reporting hepatitis B virus prevalence in East Africa from epidemiological studies published between 2005 to 2020 included in the data synthesis

analysis. The pooled prevalence for both FEM and REM is shown by the blue diamond.

\section{Results}

\section{Study identification}

This systematic review and meta-analysis used electronic databases to find published studies on the prevalence and predictors of HBV in east Africa. We found a total of 550 published articles. From these, 345 duplicate records were removed, and 141 articles were excluded after screening of the title and abstract because they were not relevant to east Africa. After this, a total of 204 full-text papers were assessed for eligibility based on the aforementioned inclusion and exclusion criteria. Out of these, 122 records were excluded because they investigated hepatitis $\mathrm{A}$ virus (HAV), hepatitis $\mathrm{C}$ virus ( $\mathrm{HCV}$ ), hepatitis D virus (HDV), or hepatitis E virus (HEV); 3 were excluded because they had insufficient data; 4 , because they had a sample size $<100 ; 8$, because they used purposive sampling; 1 , because it did not describe its sampling method; 1 , because it detected HBV delta antibodies; 28, because they were published before 2005; and 1, because it was a pre-print. Thirty-seven studies were included in the final quantitative meta-analysis (Fig. 1). They had a total sample size of 525,955 (five hundred twenty-five thousand nine hundred and fiftyfive), and included 22,156 (twenty-two thousand one hundred and fifty-six) hepatitis B surface antigen positive (HBsAg+) cases.

\section{The characteristics of the studies included}

The characteristics of the eligible studies included in our meta-analysis are shown in Table 2 . In brief, of the 37 eligible studies, the largest group was done in Tanzania $(13 / 37,35.1 \%)$ with a total sample size of 24,188 ; followed by Uganda $(9 / 37,24.3 \%)$ with a sample size of 17,103 ; Rwanda $(7 / 37,18.9 \%)$ with a sample size of 472,532 ; and Kenya $(6 / 37,16.2 \%)$ with a sample size of 2668; while Burundi and South Sudan had one eligible study each, with sample sizes of 8933 and 280,

Table 3 Subgroup analysis of the HBV pooled prevalence estimation in East Africa from 2005 to 2020

\begin{tabular}{|c|c|c|c|c|c|c|c|}
\hline \multicolumn{2}{|l|}{ Sub-groups } & \multirow[b]{2}{*}{ No } & \multicolumn{2}{|c|}{ Analysis of HBV prevalence } & \multicolumn{2}{|c|}{ Analysis of heterogeneity } & \multirow[b]{2}{*}{ Model } \\
\hline Variable & Category & & Prevalence $\%(95 \% \mathrm{Cl})$ & $P$ value & $\mathrm{I}^{2} \%(95 \% \mathrm{Cl})$ & P het & \\
\hline & Kenya & 6 & 8.54 (5.09 to 12.76) Ref & & 92.36 (86.11 to 95.79) & $<0.0001$ & Random \\
\hline \multirow[t]{3}{*}{ Country } & Uganda & 9 & 8.454 (5.76 to 11.73$)$ & 0.9637 & 97.28 (96.15 to 98.08 ) & $<0.0001$ & Random \\
\hline & Rwanda & 7 & 4.06 (3.80 to 4.34$)$ & $<0.0001^{*}$ & 85.39 (71.83 to 92.42$)$ & $<0.0001$ & Random \\
\hline & Tanzania & 13 & 5.16 (4.24 to 6.17$)$ & $0.0006^{*}$ & 80.65 (67.84 to 88.35$)$ & $<0.0001$ & Random \\
\hline \multirow[t]{3}{*}{ Year of Publication } & $2011-2015$ & 10 & 8.759 (6.09 to 11.85 ) Ref & & 95.65 (93.65 to 97.2) & $<0.0001$ & Random \\
\hline & $2005-2010$ & 8 & 6.95 (5.11 to 9.05$)$ & 0.1208 & 87.4 (77.34 to 92.98$)$ & $<0.0001$ & Random \\
\hline & $2016-2020$ & 19 & 4.388 (3.901 to 4.903$)$ & $<0.0001^{*}$ & 96.17 (95.04 to 97.04$)$ & $<0.0001$ & Random \\
\hline \multirow[t]{2}{*}{ Sampling Technique } & Probability & 11 & 7.799 (5.182 to 10.897$)$ & & 98.45 (97.99 to 98.80$)$ & $<0.0001$ & Random \\
\hline & Non-probability & 26 & 5.361 (4.567 to 6.215 ) & $<0.0001^{*}$ & 96.91 (96.21 to 96.49) & $<0.0001$ & Random \\
\hline \multirow[t]{4}{*}{ Diagnostic Technique } & ELISA & 14 & 5.214 (4.71 to 5.74) Ref & & 90.48 (85.79 to 93.62 ) & $<0.0001$ & Random \\
\hline & RDT & 15 & 6.638 (4.997 to 8.493) & $0.0126^{*}$ & 94.18 (91.88 to 95.83 ) & $<0.0001$ & Random \\
\hline & EIA & 4 & 6.127 (1.259 to 14.303$)$ & 0.2349 & 99.62 (99.50 to 99.72 ) & $<0.0001$ & Random \\
\hline & Others & 4 & 3.924 (3.697 to 4.16$)$ & 0.0622 & 22.55 (0.00 to 90.00$)$ & 0.257 & Fixed \\
\hline
\end{tabular}




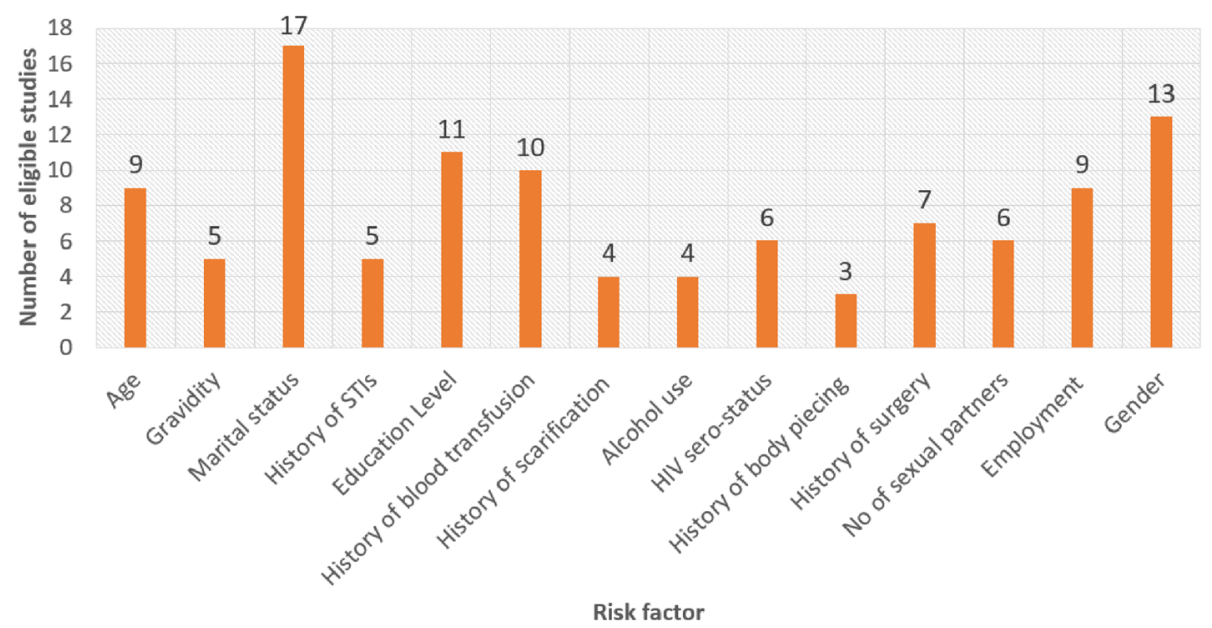

Fig. 7 Number of studies with disaggregated data on risk factors associated with HBV infection

respectively (Figs. 2 and 3, Table 2). Of the 37 eligible studies, Pirillo et al. [40] had the smallest sample size (of 164), while Makuza et al. [37] had the largest sample size $(327,360)$. Most studies $(26 / 37,70.3 \%)$ with a total sample size of 188,090 used non-probability sampling, while studies that used probability sampling (11/37, 29.7\%) had a sample size of 337,865 . Most of the eligible studies used rapid diagnostic tests (RDTs) $(15 / 37,40.4 \%)$ and enzyme-linked immunosorbent assay (ELISA) (14/37, $37.8 \%$ ), with sample sizes of 25,411 and 455,954 , respectively. Isolated studies used enzyme immunoassay (EIA) for detection of HBsAg $(4 / 37,10.8 \%)$, with a sample size of 17,065 . Other studies $(4 / 37,10.8 \%)$ used the Abbott ARCHITECT system [26], chemiluminescent enzyme immunoassay (CLEIA) [28], and the microparticle enzyme immunoassay (MEIA) [45, 56], with respective sample sizes of 13,121; 21,337; and 587 (Table 2, Fig. 3). Most of the eligible studies included in our metaanalysis were published between 2016 and 2020 (19/37, $51.4 \%$ ), with a sample size of 494,748 , followed by those published between 2011 and 2015 (10/37, 27.0\%), with a sample size of 22,021. The rest were published between 2005 and $2010(8 / 37,21.6 \%)$, with a sample size of 9180 (Table 2, Fig. 3).

\section{Prevalence of hepatitis B in the east Africa region}

The prevalence of hepatitis $B$ in east African between 2005 and 2020 varied, widely ranging from 1.05\% (95\% $\mathrm{CI}=0.845$ to $1.278 \%$ ) [54] to $20.896 \%$ (95\% $\mathrm{CI}=16.188$ to $26.260 \%$ ) [52] (Fig. 4). The overall HBV pooled prevalence among the sample of 525,955 (five hundred twenty-five thousand nine hundred and fifty-five) and 22,156 (twenty-two thousand one hundred and fifty-six) cases was $6.025 \%$ (95\% CI $=5.414$ to $6.667 \%)$ with a heterogeneity $\left(\mathrm{I}^{2}\right)$ of $97.55 \%(P>0.0001)$ (Fig. 4$)$. The Begg's test demonstrated no evidence of publication bias among the analysis $(p=0.8106)$ (Fig. 5), despite a mild funnel plot asymmetry (Fig. 6).

\section{Meta-analysis of subgroups}

As shown in Table 3 and Fig. 3, we subdivided our meta-analysis into groups, which included the country where the study was conducted, the year of publication, the sampling technique, and the HBsAg diagnostic technique. Burundi and South Sudan were left out from subgroup analyses because each country had only one eligible study. In all the sub-group analyses, the heterogeneity remained high $\left(\mathrm{I}^{2}>89 \%, p<0.0001\right)$, but was lower for 'other diagnostic tests' besides ELISA, RDT, and EIA $\left(\mathrm{I}^{2}=22.55 \%, p=0.257\right)$.

By country, Kenya had the highest prevalence of $8.54 \%$ (95\% CI $=5.09$ to $12.76 \%)$ from 6 studies closely followed by Uganda with a pooled prevalence of $8.454 \%$ $(95 \% \mathrm{CI}=5.76$ to $11.73 \%)$ from 9 studies and then Tanzania with a prevalence of $5.16 \%$ (95\% CI $=4.24$ to 6.17\%) from 13 studies. The lowest HBV prevalence was registered in Rwanda, with $4.06 \%$ (95\% CI $=3.80$ to 4.34\%) among 7 studies (Supplementary materials S1-S4, Figures A-D).

Regarding the year of publication, the lowest pooled prevalence was $4.388 \%(95 \% \mathrm{CI}=3.901$ to $4.903 \%)$ found in 19 studies published between 2016 and 2020, closely followed by a prevalence of $6.95 \%$ (95\% CI $=5.11$ to 9.05\%) from 8 studies published between 2005 and 2010 . The highest prevalence of $8.759 \%$ (95\% CI $=6.09$ to $11.85 \%)$ was pooled from 10 published studies between 2011 and 2015 (Supplementary Materials S5-7, Figures E-G).

Pertaining to the sampling technique, the pooled prevalence among the 26 studies that used nonprobability methods was $5.361 \% \quad(95 \% \mathrm{CI}=4.567$ to $6.215 \%$ ), while the pooled prevalence for the 11 
Table 4 Analysis of the risk factors associated with HBV infection in East Africa

\begin{tabular}{|c|c|c|c|c|c|c|c|}
\hline \multirow[b]{2}{*}{ Risk factor } & \multirow[b]{2}{*}{ Category } & \multirow[b]{2}{*}{ Number } & \multicolumn{2}{|c|}{ Analysis of HBV prevalence } & \multicolumn{3}{|c|}{ Analysis of heterogeneity of studies } \\
\hline & & & Proportion $\%,(95 \% \mathrm{Cl})$ & $P$ value & $\mathrm{I}^{2}, 95 \% \mathrm{Cl}$ & P het & Model \\
\hline \multirow[t]{2}{*}{ Age } & $<20$ years & 9 & 4.796 (1.88 to 8.97$)$ & & 80.6 (64.07 to 89.54$)$ & $<0.0001$ & Random \\
\hline & $>20$ years & 9 & 5.74 (3.52 to 8.46$)$ & 0.28 & 89.27 (81.9 to 93.65$)$ & $<0.0001$ & Random \\
\hline \multirow[t]{2}{*}{ Gravidity } & Primigravida & 5 & 2.84 (1.37 to 4.82$)$ & & $81.6(57.40$ to 92.06$)$ & 0.0002 & Random \\
\hline & Multigravida & 5 & 3.84 (3.40 to 4.33$)$ & $0.0006^{*}$ & 32.98 (0.00 to 74.58 & 0.2015 & Fixed \\
\hline \multirow[t]{2}{*}{ Marital status } & Married & 17 & 5.508 (3.35 to 8.17$)$ & & 98.91 (98.69 to 99.1 ) & $<0.0001$ & Random \\
\hline & Not Married & 17 & $8.644(5.21$ to 12.85$)$ & $<0.0001^{*}$ & 96.98 (96.13 to 97.6$)$ & $<0.0001$ & Random \\
\hline \multirow[t]{2}{*}{ History of STIs } & Yes & 5 & $7.33(4.77$ to 10.67$)$ & & $25.7(0.00$ to 70.27$)$ & 0.2015 & Fixed \\
\hline & No & 5 & 4.41 (2.79 to 6.39$)$ & 0.5858 & $68.61(19.22$ to 87.8$)$ & 0.0126 & Random \\
\hline \multirow[t]{2}{*}{ Education Level } & Primary \& below & 11 & 6.096 (4.42 to 8.02 ) & & 83.49 (71.9 to 90.29$)$ & $<0.0001$ & Random \\
\hline & Secondary \& above & 11 & 5.917 (4.374 to 7.676$)$ & 0.6434 & 73.11 (50.84 to 85.3 ) & 0.0001 & Random \\
\hline \multirow[t]{2}{*}{ History of blood transfusion } & Yes & 10 & 11.057 (5.84 to 17.68$)$ & & 79.6 (63.2 to 88.72$)$ & $<0.0001$ & Random \\
\hline & No & 10 & 4.915 (3.492 to 6.567$)$ & $<0.0001^{*}$ & 89.5 (82.74 to 93.56$)$ & $<0.0001$ & Random \\
\hline \multirow[t]{2}{*}{ History of scarification } & Yes & 4 & 8.102 (4.47 to 12.696$)$ & & 89.7 (78.79 to 95.0$)$ & $<0.0001$ & Random \\
\hline & No & 4 & 5.049 (3.318 to 7.120$)$ & $<0.0001^{*}$ & 84.4 (65.09 to 93.04$)$ & $<0.0001$ & Fixed \\
\hline \multirow[t]{2}{*}{ Alcohol use } & Yes & 4 & 7.37 (3.46to 12.6) & & 64.88 (0.00 to 88.09$)$ & 0.036 & Random \\
\hline & No & 4 & 3.48 (2.55 to 4.63$)$ & 0.4703 & 30.01 (0.00 to 74.53 ) & 0.2322 & Fixed \\
\hline \multirow[t]{2}{*}{ HIV sero-status } & Positive & 6 & 12.131 (7.92 to 17.52$)$ & & 12.15 (0.00 to 78.35$)$ & 0.3374 & Fixed \\
\hline & Negative & 6 & 5.863 (3.082 to 9.461$)$ & $0.0030^{*}$ & 89.81 (80.5 to 94.67$)$ & $<0.0001$ & Random \\
\hline \multirow[t]{2}{*}{ History of body piecing } & Yes & 3 & 3.813 (2.41 to 5.70$)$ & & 59.57 (0.00 to 88.48$)$ & 0.0843 & Fixed \\
\hline & No & 3 & 4.24 (2.903 to 5.95) & 0.9394 & 0.00 (0.00 to 92.27$)$ & 0.6478 & Fixed \\
\hline \multirow[t]{2}{*}{ History of surgery } & Yes & 7 & $13.2(0.003$ to 45.2$)$ & & 99.50 (99.37 to 99.60$)$ & $<0.0001$ & Random \\
\hline & No & 7 & $4.85(1.43$ to 10.14$)$ & $<0.0001^{*}$ & 97.32 (96.0 to 38.20 & $<0.0001$ & Random \\
\hline \multirow[t]{2}{*}{ No of sexual partners } & One & 6 & 5.116 (3.124 to 7.566$)$ & & 89.04 (78.8 to 94.34$)$ & $<0.0001$ & Random \\
\hline & More than one & 6 & 9.53 (5.509 to 14.512 ) & $<0.0001^{*}$ & 87.36 (74.9 to 93.65$)$ & $<0.0001$ & Random \\
\hline \multirow[t]{2}{*}{ Employment } & Formal & 9 & 7.70 (2.38 to 15.69$)$ & & 95.65 (93.51 to 97.1 ) & $<0.0001$ & Random \\
\hline & Non formal & 9 & 10.48 (2.72 to 22.5$)$ & 0.333 & 98.6 (98.12 to 98.93 ) & $<0.0001$ & Random \\
\hline \multirow[t]{2}{*}{ Gender } & Male & 13 & 8.561 (6.66 to 10.675 ) & & 93.53 (90.6 to 95.54 ) & $<0.0001$ & Random \\
\hline & Female & 13 & 6.986 (4.841 to 9.491$)$ & $0.0007^{*}$ & 96.63 (95.44 to 97.5 ) & $<0.0001$ & Random \\
\hline
\end{tabular}

ST/s Sexually Transmitted Infections

${ }^{*} P$ value of risk factor $<0.05$ statistically significant

eligible studies that used probability methods was $7.799 \% \quad(95 \% \mathrm{CI}=5.182$ to $10.897 \%)$. Concerning HBsAg detection method, the 14 studies that used ELISA reported a prevalence rate of $5.214 \%(95 \% \mathrm{CI}=$ 4.71 to $5.74 \%)$, the 15 studies that used RDT reported a prevalence rate of $6.638 \%(95 \% \mathrm{CI}=4.997$ to $8.493 \%)$ and the 4 studies that used EIA reported a pooled prevalence of $6.127 \%(95 \% \mathrm{CI}=1.259$ to $14.303 \%)$. The studies that used other diagnostic tests (MEIA, CLEIA, and AAS) reported a pooled HBV prevalence of $3.924 \%$ (95\% CI $=3.697$ to $4.16 \%$ ) (Supplementary Materials S8-11, Figures H-K).

When we analysed the relative prevalence of HBV by country, year of publication, sampling technique, and method of HBsAg detection, Kenya and Uganda had significantly higher HBV pooled prevalence than Tanzania and Rwanda $(P<0.05)$. Similarly, articles published from 2011 to 2015 had a significantly higher HBV prevalence than those published from 2005 to 2010 and from 2016 to $2020(P<0.05)$. Further still, studies that detected the HBsAg using RDT reported significantly higher HBV prevalence than those that used ELISA (Table 3).

\section{Predictors of $\mathrm{HBV}$ infection in east Africa}

Of all the records eligible for inclusion in our metaanalysis, 9 had disaggregated data on age $(<20$ or $\geq 20$ years); 5 , on gravidity (primagravida or multigravida); 17 , on marital status (married or unmarried); 5, on history of sexually transmitted infections (prior infection or no); 11 , on education level ( $\leq$ primary or $\geq$ secondary); 10 , on history of blood transfusion (prior transfusion or no); 4 , on history of scarification (body scarification or naïve); 4, on alcohol use (yes or no); 6, on HIV serostatus 
Table 5 Analysis of the statistically significant risk factors associated with HBV infection in East Africa

\begin{tabular}{|c|c|c|c|c|c|}
\hline \multirow[b]{2}{*}{ Risk factor } & \multicolumn{2}{|l|}{ Analysis } & \multirow[b]{2}{*}{$P$ value } & \multirow[b]{2}{*}{ Heterogeneity $\left(I^{2} \%\right)$} & \multirow[b]{2}{*}{ Model } \\
\hline & Number & Relative risk $\%(95 \% \mathrm{Cl})$ & & & \\
\hline Marriage & 18 & 1.592 (0.535 to 4.732 ) & 0.403 & 99.08 & Random \\
\hline Gravidity & 5 & 0.856 (0.448 to 1.634$)$ & 0.637 & 61.66 & Random \\
\hline History of blood transfusion & 10 & 1.950 (1.114 to 3.413$)$ & $0.019^{*}$ & 76.89 & Random \\
\hline Scarification & 4 & 1.204 (1.154 to 1.257$)$ & $<0.001^{*}$ & $6.39 \%$ & Fixed \\
\hline HIV sero-positivity & 6 & 2.227 (1.039 to 4.772 ) & $0.039^{*}$ & $64.96 \%$ & Random \\
\hline History of surgery & 7 & 2.47 (0.14 to 43.63$)$ & 0.537 & 99.22 & Random \\
\hline$\geq 2$ sexual partners & 6 & 2.161 (1.085 to 4.305$)$ & $0.028^{*}$ & 86.36 & Random \\
\hline Male sex & 12 & $1.312(1.268$ to 1.357$)$ & $<0.001^{*}$ & 49.72 & Fixed \\
\hline
\end{tabular}

${ }^{*} P$ value of risk factor $<0.05$ statistically significant

(HIV+ or HIV-); 3, on history of body piercing (prior body piercing or naïve); 7 , on history of surgery (underwent surgery before or not); 6 , on number of sexual partners ( 1 or $\geq 2$ ); 9, on employment (formal or informal); and 13, on sex (male or female) (Fig. 7).

\section{Meta-analysis of the predictors of HBV infection in east Africa}

When we analysed the data that investigated the predictors of HBsAg seropositivity by age, gravidity, marital status, sexually transmitted infection, level of education, blood transfusion, scarification, alcohol use, HIV serostatus, body piercing, surgery, person who have sex with multiple partners, and gender, the results were interesting. The HBV prevalence was significantly associated with multigravidity (3.84\%; $95 \% \mathrm{CI}=3.40$ to $4.33 \%$ ); singleness $8.644 \%(95 \% \mathrm{CI}=5.21$ to $12.85 \%)$; blood transfusion $11.057 \%(95 \% \mathrm{CI}=5.84$ to $17.68 \%)$; scarification $8.102 \%(95 \% \mathrm{CI}=4.47$ to $12.696 \%)$; HIV seropositivity
$12.131 \%(95 \% \mathrm{CI}=7.92$ to $17.52 \%)$; surgery $(13.2 \%$; $95 \%$ $\mathrm{CI}=0.003$ to $45.2 \%$ ); having sex with multiple partners $9.53 \%(95 \% \mathrm{CI}=5.509$ to $14.512 \%)$; and being male $8.561 \%(95 \% \mathrm{CI}=6.66$ to $10.675 \%)(P<0.05)$. However, we found no significant association between age, sexually transmitted infections, education level, alcohol use, body piercing, or employment with the risk of HBV infection $(P>0.05)$. For most of the risk factor meta-analyses, heterogeneity remained high $\left(\mathrm{I}^{2}>80 \%, \mathrm{P}_{\text {het }}<0.0001\right)$, but it was reduced for multigravidity, history of STIs, secondary level of education, routine alcohol use, HIV seropositivity, and body piercing $\left(\mathrm{I}^{2}<73 \%, \quad \mathrm{P}_{\text {het }}>0.0001\right)$ (Table 4).

\section{Relative risk meta-analysis for hepatitis B virus infection in east Africa}

To investigate the relative risk for HBV infection in east Africa, we meta-analysed the data on the statistically significant predictors of $\mathrm{HBV}$ infection, as presented in

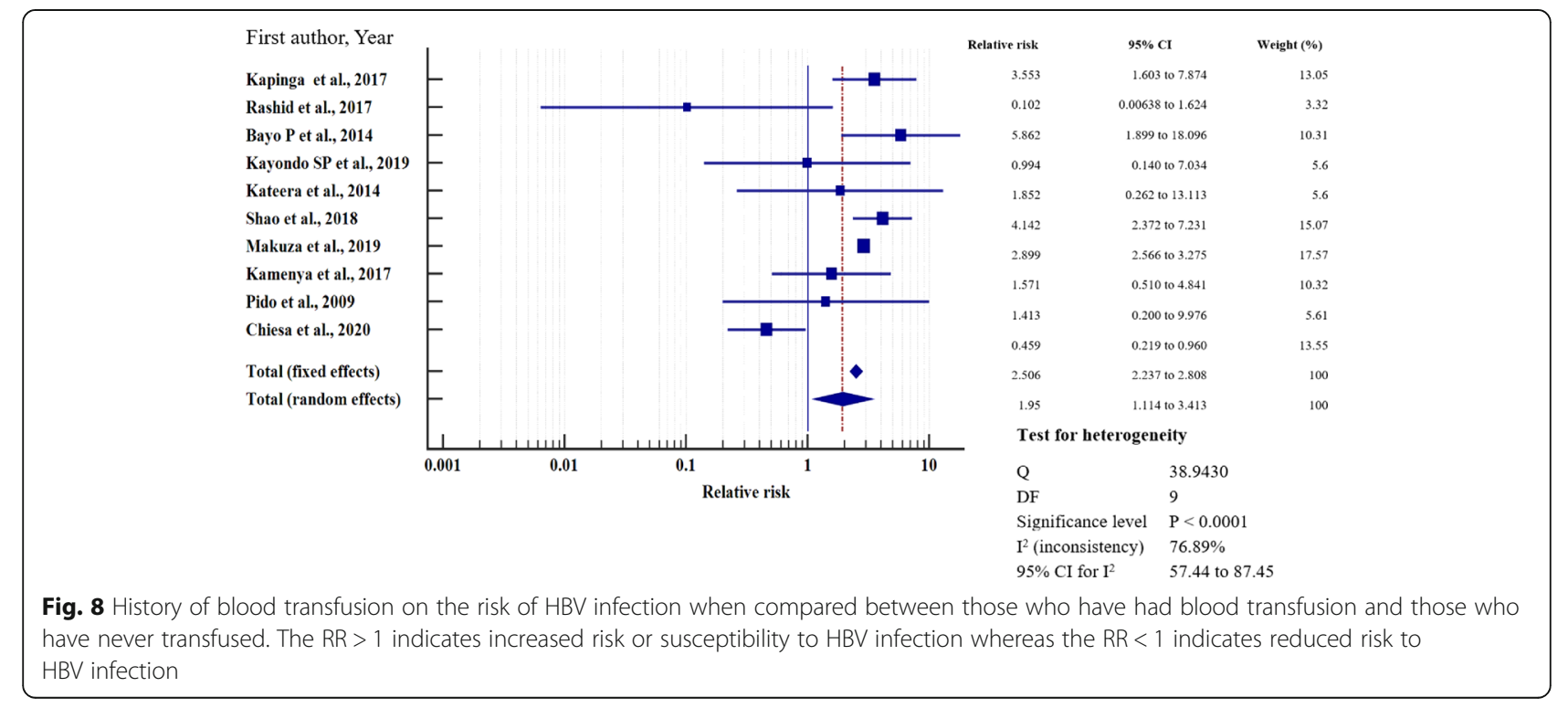




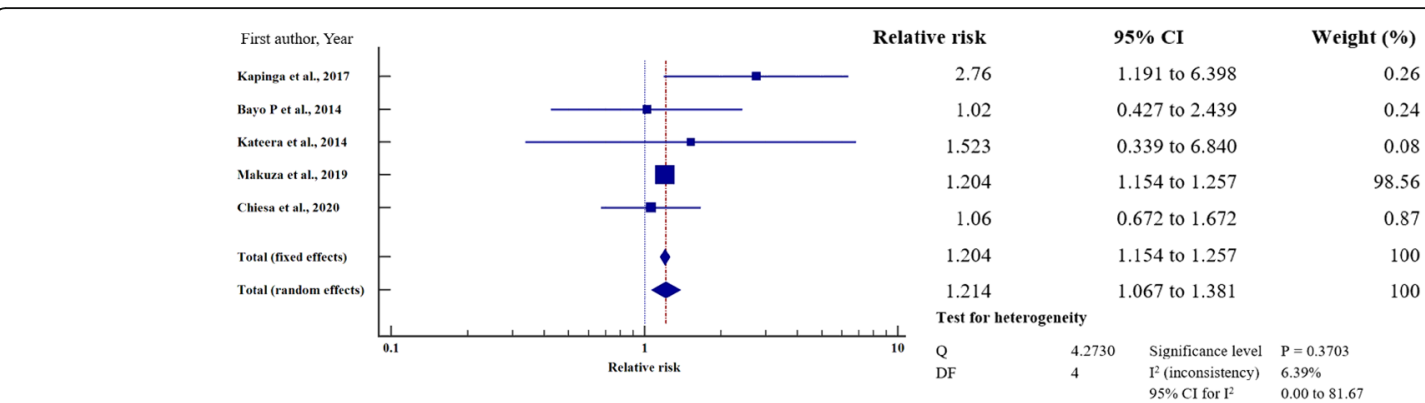

Fig. 9 History of scarification on the risk of HBV infection when compared between those with the history of scarification and those who have never scarified. The RR $>1$ indicates increased risk or susceptibility to HBV infection whereas the RR $<1$ indicates reduced risk to HBV infection

Table 4. Based on this criterion, eight factors (marital status, gravidity, blood transfusion, scarification, HIV seropositivity, surgery, having sex with multiple partners, and gender) merited relative risk meta-analysis (Table 5). The independent risk factors significantly associated with HBV infection were blood transfusion (relative risk 1.950, $95 \% \mathrm{CI}=1.114$ to $3.413 \%, P=0.019$ ); body scarification (relative risk $1.204,95 \% \mathrm{CI}=1.154$ to $1.257 \%, P<0.001$ ); HIV seropositivity (relative risk $2.227,95 \% \mathrm{CI}=1.039$ to $4.772 \%, P=0.039$ ); having sex with multiple partners (relative risk $2.161,95 \% \mathrm{CI}=1.085$ to $4.305 \%, P=0.028$ ); and being male (relative risk $1.312,95 \% \mathrm{CI}=1.268$ to $1.357 \%$, $P<0.001$ ) (Table 5, Figs. 8, 9, 10, 11, 12). For most of the analyses, heterogeneity index $\left(\mathrm{I}^{2}\right)$ remained high $(>85 \%)$, but it was lower for scarification $\left(\mathrm{I}^{2}=23.31 \%\right)$ and vanished for HIV seropositivity $\left(\mathrm{I}^{2}=0.00 \%\right.$ ) (Table 5$)$. Conversely, marital status (relative risk $1.592,95 \% \mathrm{CI}=0.535$ to $4.732 \%, P=0.403$ ), magnitude of gravidity (relative risk $0.856,95 \% \mathrm{CI}=0.448$ to $1.634 \%, P=0.637$ ), and surgery (relative risk $2.47,95 \% \mathrm{CI}=0.14$ to $43.63 \%, P=0.537$ ) were not significantly associated with the risk of HBV infection $(P>0.05)$ (Table 5, Figs. 13, 14, 15).

\section{Meta-regression}

We performed meta-regression analysis on the two continuous variables of sample size and year of publication to assess how they varied with the prevalence of HBV. There was no statistical significance in either regression $(P>0.05)$ (Fig. 16), suggesting that the results are robust and the overall HBV prevalence is not directly influenced by sample size or year of publication.

\section{Sensitivity analysis}

For sensitivity analysis, we removed the study with the largest sample size [37]. The overall $\mathrm{HBsAg}+$ pooled prevalence rate before omission was $6.025 \%$ (95\% CI $=$ 5.414 to $6.667 \%)$ with a heterogeneity $\left(\mathrm{I}^{2}\right)$ of $97.55 \%, P>$ 0.0001 . After the omission, the pooled prevalence rate increased slightly to $6.149 \%(95 \% \mathrm{CI}=5.297$ to $7.06 \%)$, with a heterogeneity $\left(\mathrm{I}^{2}\right)$ of $97.43 \%, P<0.0001$. Thus, the calculated pooled prevalence was not affected by a single study, suggesting that the results are robust (Fig. 17). Furthermore, Begg's correlation test for publication bias after omitting the study did not show evidence of publication bias $(P=0.9166)$ (Figs. 18), despite the mild right skew of the data in the funnel plot (Fig. 19).

\section{Discussion}

In our meta-analysis, almost all the eligible studies were cross-sectional and reflected the HBV prevalence at one point in time, ranging from 1.05 to $20.896 \%$, with a pooled prevalence of $6.025 \%$. In $37.8 \%$ of the studies

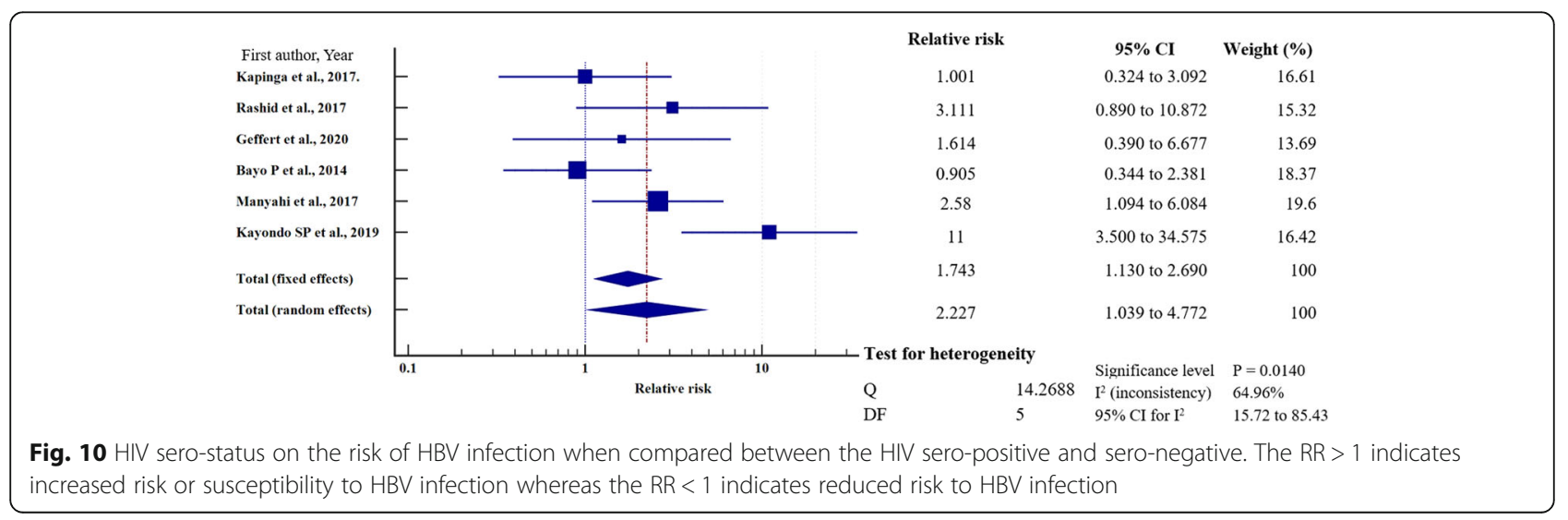




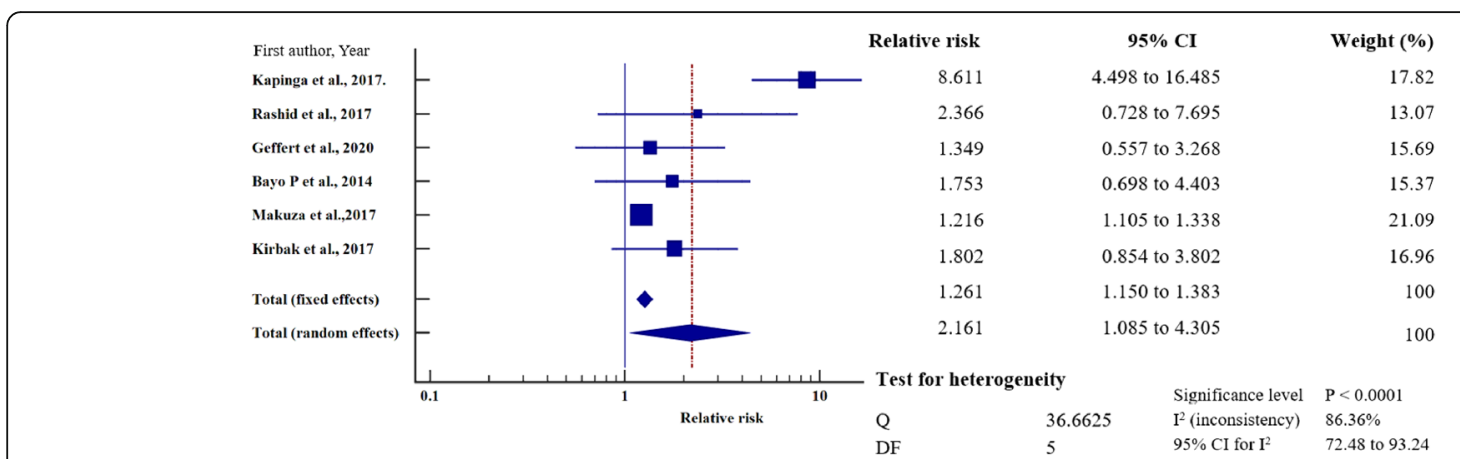

Fig. 11 Number of sexual partners on the risk of HBV infection when compared those with one sexual partner and those with multiple sexual partners. The RR $>1$ indicates increased risk or susceptibility to HBV infection whereas the RR $<1$ indicates reduced risk to HBV infection

(14/37), the prevalence was higher than the $6.1 \%$ reported by the World Health Organization (WHO) in the African region [4]. Thus, HBV is still a significant burden in east Africa, aggravated by the weak health care systems in the region. Furthermore, the burden is a challenge all over Africa because many meta-analyses conducted in other African countries found even higher pooled prevalence than the prevalence reported in the current study. For example, in Nigeria, the prevalence was 13.6\% [57]; in Ghana, 12.3\% [58]; in Cameroon, $10.6 \%$ [59]; in Burkina Faso, 11.21\% [60]; in Sudan, $12.07 \%$ [61]; and in Somalia, 19.0\% [62]. Consequently, the results of our meta-analysis and those of other metaanalyses show that HBV is hyperendemic in many African countries [29] and that a significant budgetary resource allocation by African governments in general and the EAC member states in particular is needed to address the burden.

Pooling the prevalence of HBV by country, Kenya had the highest prevalence rate of $8.54 \%$, followed by Uganda (8.454\%) and Tanzania (5.16\%), and finally Rwanda with the lowest prevalence (4.1\%). The prevalence rates reported in our study for Uganda, Kenya, and Tanzania are in fair conformity with the respective prevalence rates of 9.2, 5.2, and $7.2 \%$ reported by Schweitzer A. et al. [63] in their systematic review and meta-analysis on the global prevalence of HBV. The differences in prevalence rates of HBV by country cannot be ascertained exactly, but can probably be explained by differences in infection risk factors [63], vaccination coverage by country [64], endemicity [62], prevention and control measures [65], host genetic factors, and infectivity of the HBV genotypes circulating in the regions [66].

For countries with low prevalence rates, it is plausible that there have been concerted efforts by both the health care workers and community members to improve HBV awareness, as reported in primary studies by Quadri et al. [67] and Shah et al. [68] for Tanzania. On the other hand, for countries with high prevalence rates, it is possible that there has been an increase in high-risk behaviours, such as unprotected sex, tattooing, and traditional scarification, combined with low levels of HBV awareness, as reported in primary studies conducted in Kenya by Awili et al. [69] and Ngaira et al. [42].

The high prevalence of HBV in Uganda has earlier been reported by Ott et al. in their study on time trends of global chronic HBV infection [70]. However, the high HBV prevalence rate in Uganda should be interpreted with caution, since many of the Ugandan studies eligible for inclusion in our meta-analysis were conducted on $\mathrm{HIV}+$ cohorts at the Infectious Diseases Institute (IDI) [13], at the Joint Clinical Research Council (JCRC) [71],

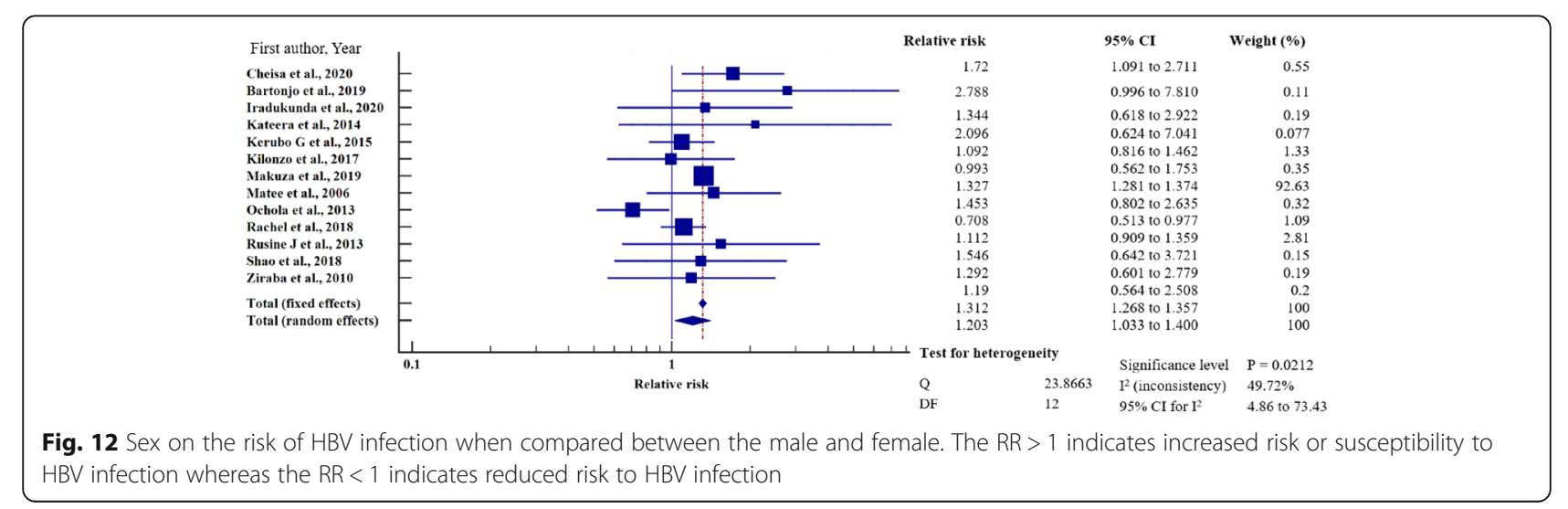




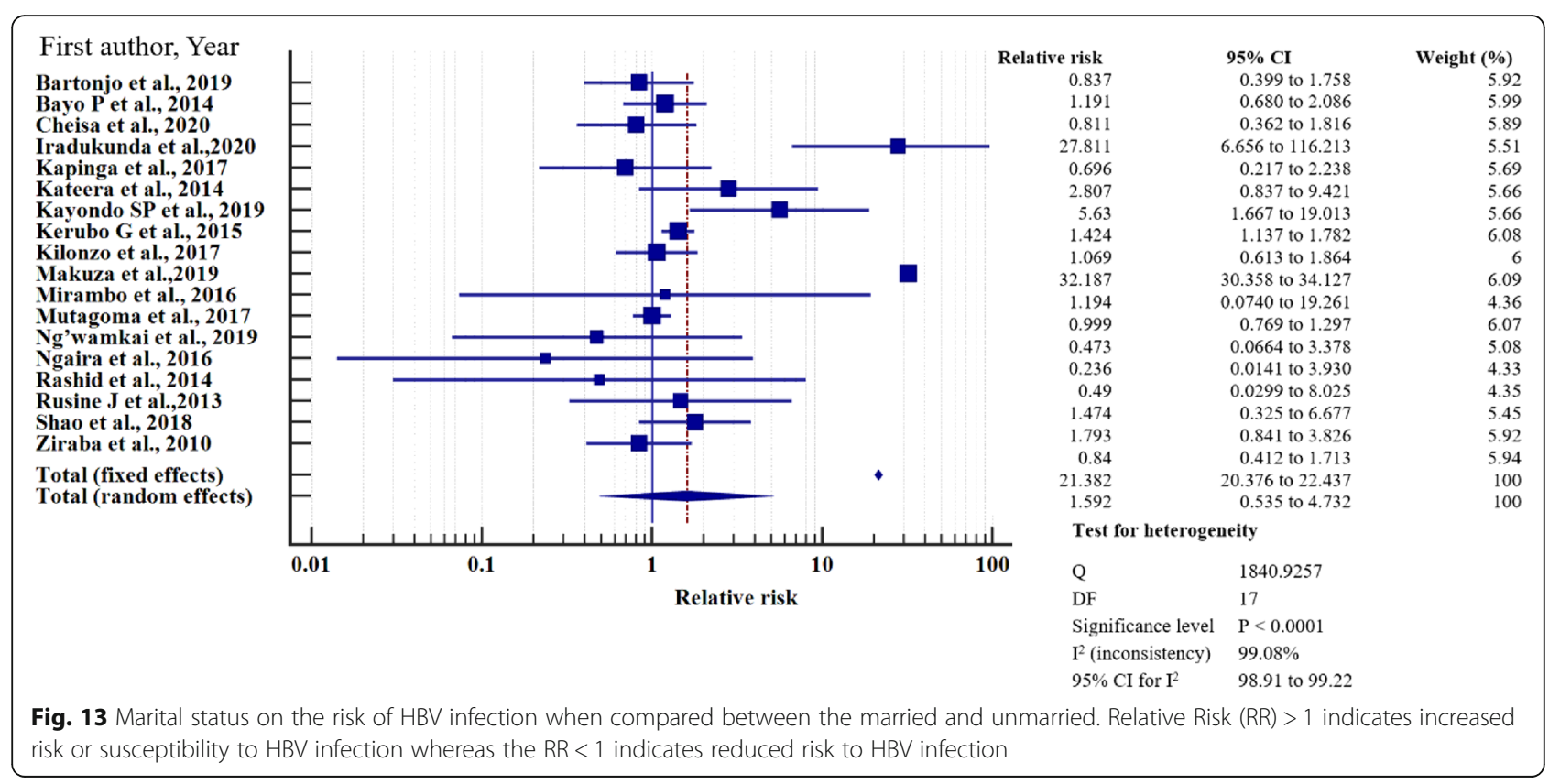

under the Rakai Health Sciences project [5], or in the highly endemic northern region [6]. Furthermore, many of the Ugandan studies included were published between 2010 and 2015 - a period characterised by high prevalence of HBV in Uganda, with a national prevalence of $10 \%$ in the general population and a regional prevalence as high as $21.7 \%$ in the northeast and $19.4 \%$ in the north central region [72]. This explains the higher rate of HBsAg positivity in the general population. Most importantly, in Uganda, there have been no routine care programs for HBV-infected persons. Only recently were care programs initiated, such as routine testing, vaccination programs among high-risk groups such as health workers, viral load evaluation before treatment candidacy is established, and the Kabaka Foundation's mass testing and vaccination program.

The pooled prevalence rate of HBV in Rwanda reported in our meta-analysis is analogous to the prevalence rate of $3.9 \%$ reported by the Rwanda national
HBsAg prevalence survey [37]. Rwanda, unlike other EAC member countries, has published literature on the nationwide epidemiological survey of HBV infection [37] in addition to the sub-population studies, including studies of blood donors [28], persons living with HIV [43], health care workers [10], and pregnant women attending antenatal care $[12,26]$. The low pooled prevalence of HBV in Rwanda compared to the other east African countries can be explained by the wide-scale vaccination campaign among people at high risk, ongoing since 2015 [37].

Considering the year of publication, studies published between 2011 and 2015 reported a significantly higher HBV prevalence $(8.759 \%)$ than those published from 2016 to $2020(P<0.0001)$. The dynamics underlying the periodic differences in the burden of the disease in our region can be explained by the variations in the prioritisation and target populations for HBV screening by the regional governments and

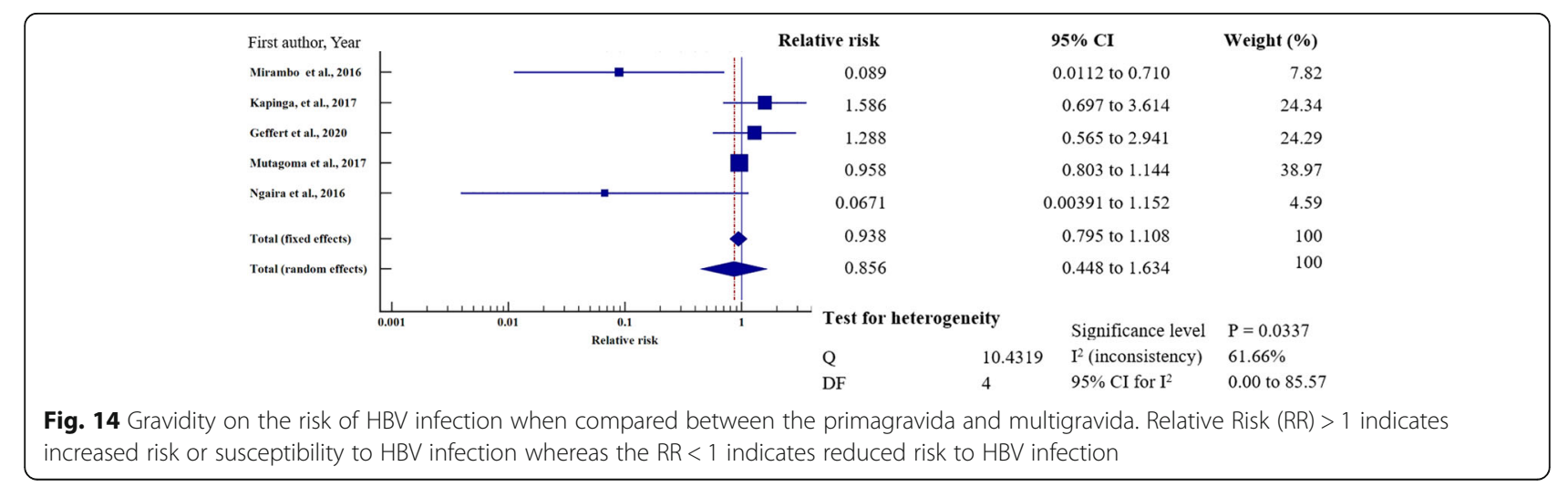




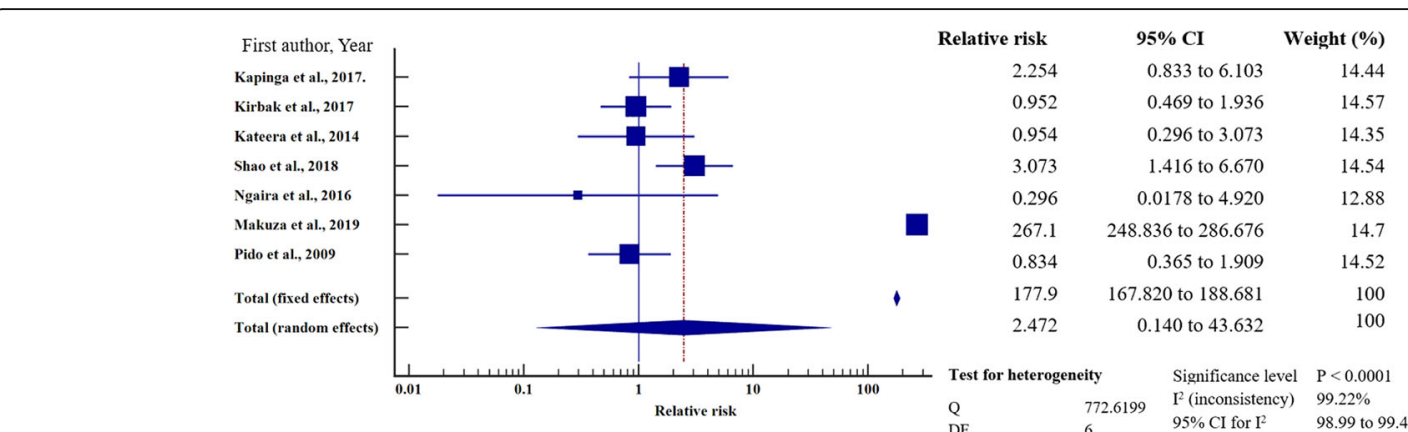

Fig. 15 History of surgery on the risk of HBV infection when compared between those previously exposed to surgical operation and those who have never. The RR $>1$ indicates increased risk or susceptibility to HBV infection whereas the RR $<1$ indicates reduced risk to HBV infection

funding organisations. Most of the studies conducted from 2010 to 2015 were targeting HBV-HIV coinfected persons. The apparently high burden of the disease in our region during this period can be explained by the shared route of transmission for both HIV and HBV [72]. The decline in the burden of the disease reported in the more recently published studies can be explained by the increased public health awareness and better vaccination coverage in our region [37]. Importantly, children born in health facilities after 2002 have been immunised against HBV as part of the expanded immunisation program contributing to herd immunity in our region [73]. Further still, publications from between 2016 and 2020 targeted participants from lower-risk groups, such as pregnant mothers attending antenatal care [39] and blood donors [28].

In terms of the screening techniques, the pooled prevalence rate obtained from published studies that had detected HBV using ELISA was significantly lower than that for studies that used RDT $(P=0.0126)$. This could be due to the higher specificity of ELISA compared to RDT [57]. Besides, RDTs have been found elsewhere to have sensitivity as low as $60 \%$, despite being a diagnostic test of choice in community-based screening for infectious diseases (including HBV) due to their ease of use and simplicity [74].

In our meta-analysis of predictors of HBV infection, persons with a history of blood transfusion were 1.950 times more likely to be HBsAg-seropositive. This risk estimate was significantly higher than for persons without prior blood transfusion. This has been also reported in the meta-analysis of the HBV infection risk factors in Ghana [58]. Thus, despite the recommendation by the WHO to screen the donated blood for HBV prior to transfusion into the recipient [75], this is still not being done routinely in our region. Our meta-analysis indicates that blood should be screened rigorously before each blood transfusion to limit HBV infections.

Similarly, the pooled HBV prevalence in our metaanalysis was significantly higher in males. Men in east Africa are 1.312 times more likely than women to be HBsAg-positive, consistently with the results from primary studies conducted in west Africa [76]. This is probably because males are exposed to riskier sexual behaviours than females, like having multiple sexual
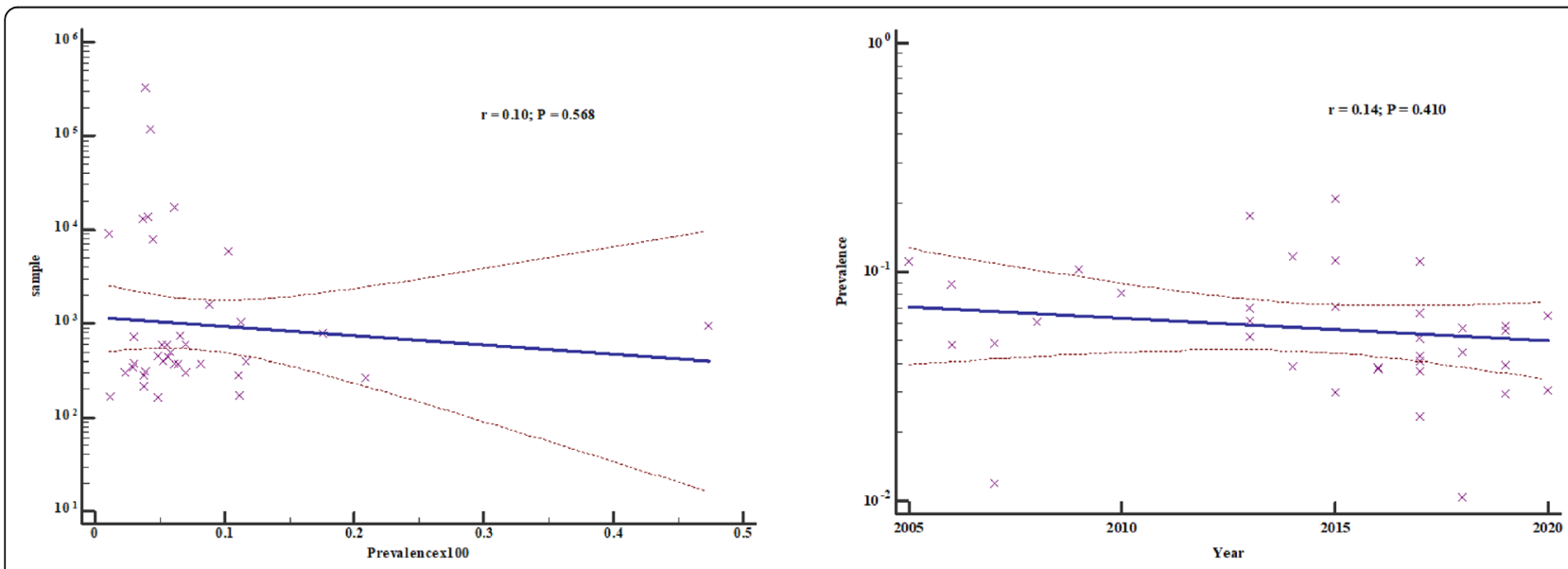

Fig. 16 Meta-regression analysis for the heterogeneity of HBV prevalence in East Africa 2005 to 2020 


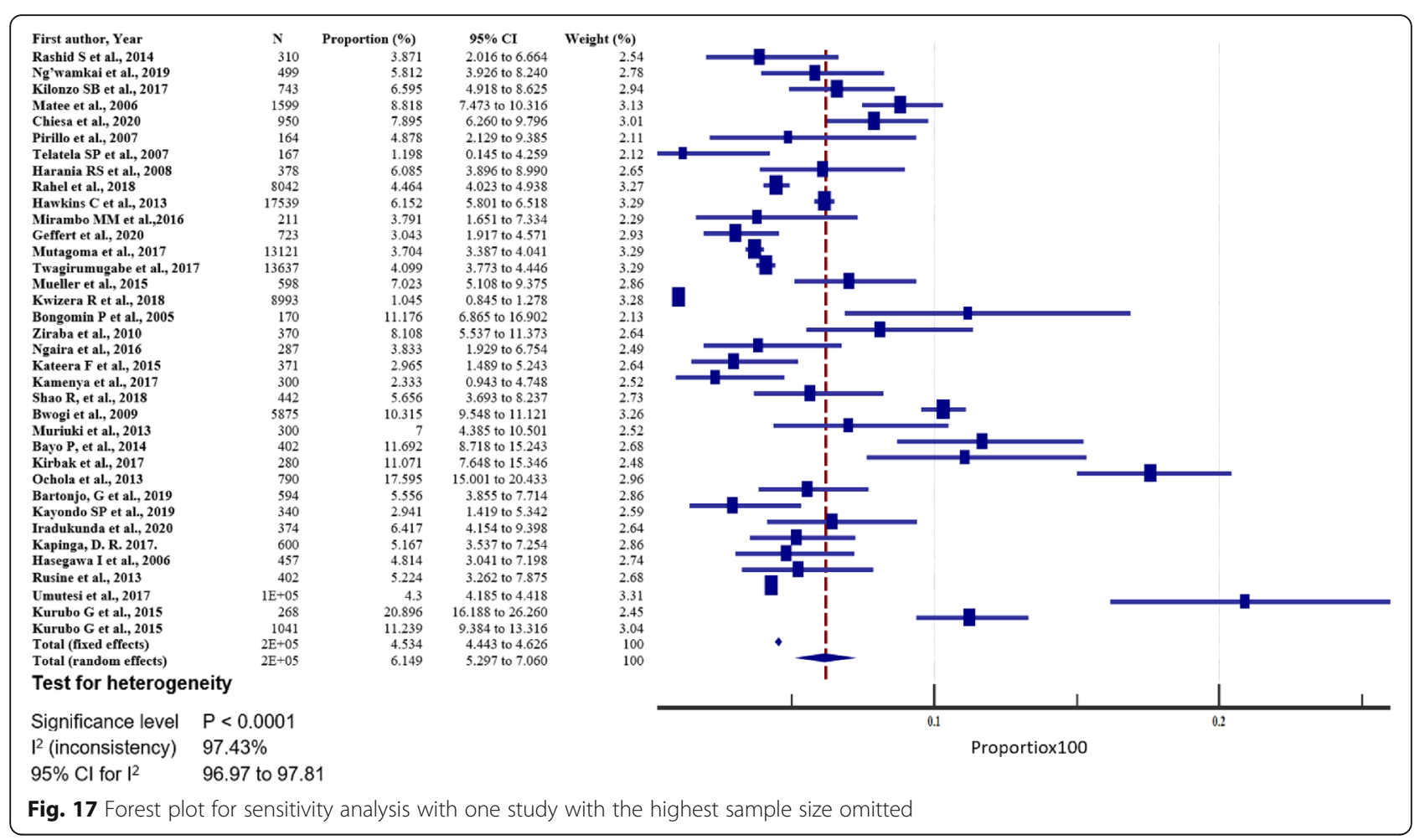

partners [77]. Unfortunately, males have a low clearance rate of HBsAg, with eventual progression to chronic infection, increasing the risk of terminal liver diseases [78]. Our results therefore suggest that men should lead the fight against the spread of HBV, since they are at a much higher risk than women. Persons who have multiple sexual partners in our region also had significantly higher pooled HBV prevalence, and their chances of contracting HBV were 2.161 times higher than those of people with one sexual partner, consistently with findings from
Nigeria [79] and India [80]. Furthermore, since HBV is a sexually transmitted disease, having multiple sexual partners increases the risk of infection. Our data suggest that sex education that promotes safe sex and good hygiene should be included in school programs and in public health awareness campaigns to reduce HBV infections. In addition, cultural and religious institutions should be brought on board to complement the school curricula and public health awareness programs in reducing promiscuity.

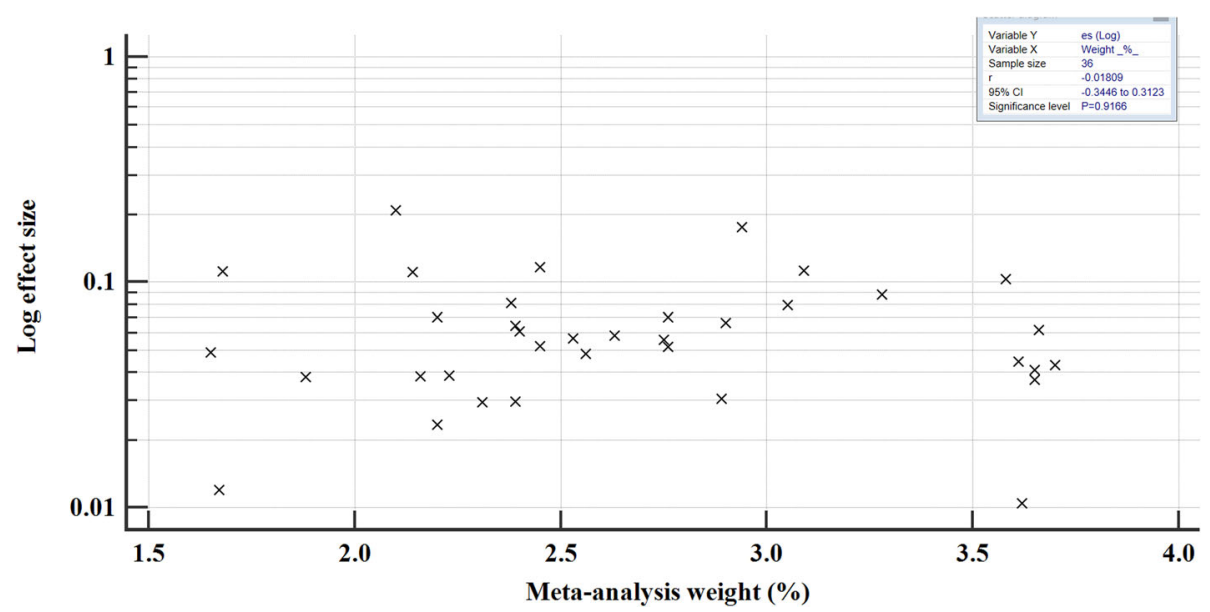

Fig. 18 Begg's correlation test for publication bias; correlation of log effect size and meta-analysis weight after exclusion of the study with the largest sample size 


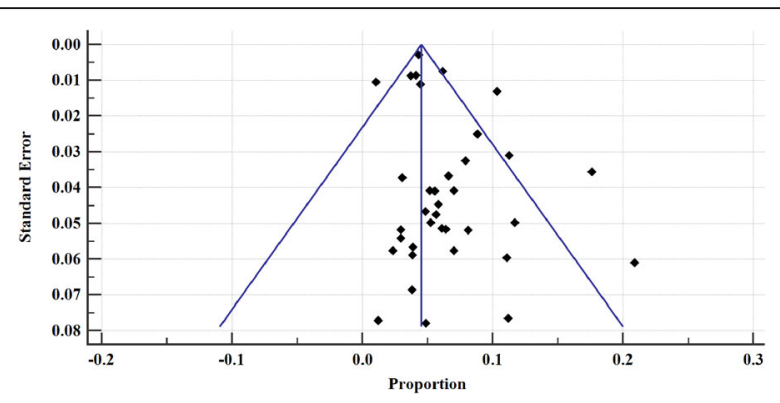

Fig. 19 Bias assessment plot for sensitivity analysis of studies reporting hepatitis B virus prevalence in East Africa from 2005 to 2020

Furthermore, HBV prevalence was significantly higher among those who practice cultural scarification. This practice significantly increased the risk of HBV infection by 1.204 , consistently with earlier reports from Sudan [81] and Ethiopia [82]. The increased risk can be explained by the use of poorly sterilised equipment during the practice. Consequently, mass sensitisation should be done to avoid cultural practices that pose a potential risk of HBV transmission. However, if the practices are deemed inevitable, as may be the case in some communities with strong ties to their cultures, a more professional approach should be adopted, such as use of sterilised or personalised equipment. Finally, HBV seropositivity was 2.227 times more likely to be linked with the risk of HIV co-infection. This is similar to findings reported from primary studies done is South Africa [83], Nigeria [84], Cameroon [85], Europe [86], and India [87]. The shared route of transmission of the two viruses is implicated in the increased risk of HBV infection among those infected with HIV [88]. Also, persons living with HIV (PLWHIV) have compromised immunity, and when they are exposed to HBV, the chances of HBV progressing to chronic infection of are higher [43]. Thus, rigorous screening of HIV-positive patients for the hepatitis B surface antigen should be introduced at lower health care facilities to assess the prevalence of coinfection in order to roll out customised treatment for coinfected persons. For the other predictors of HBV infection, including age, gravidity, education level, alcohol use, history of body piercing, and employment, findings from our meta-analysis show that host and viral factors appear to be more important in influencing the prevalence of HBV in the respective cohorts [89-91]. Worth mentioning is also that differences in vaccination coverage [64] or in health education regarding prevention of HBV transmission may account for the differences in the HBV prevalence between countries [65].

\section{Conclusion}

In conclusion, this study has provided an update on the HBV status in our region. The studies included were robust; some had very large sample sizes, and they reflect the status quo of $\mathrm{HBV}$ in our region. Moreover, most of the studies were published recently (2015 to 2020) and offer up-to-date data on HBV prevalence in our region. Our meta-analysis has identified variations in HBV endemicity in east Africa, ranging from hyperendemicity to moderate endemicity. The overall pooled prevalence and the subgroup pooled prevalence are comparable to those observed in previous studies, with minor differences due to differences in endemicity and prevention strategies. Blood transfusion, surgery, body scarification, promiscuity, and gender were independent factors associated with the risk of HBV infection. Being male was singled out as the most highly significant factor associated with the HBV burden in our region. Consequently, persons in East Africa with a history of blood transfusion, surgery, and body scarification, persons with multiple sexual partners, and male persons had higher chances of hepatitis B surface antigen seropositivity. We recommend the implementation of universal and free vaccination for all adults in the region, as well as interventions by regional governments to control and prevent the transmission of HBV, targeting the higher-risk groups such as men.

\section{Abbreviations}

AJOL: African Journal Online; CLEIA: Chemiluminescent enzyme immunoassay; EAC: East African community; ElA: Enzyme Immuno Assay; ELISA: Enzyme Linked Immunosorbent Assay; FEM: Fixed effect model; HBCAb: Hepatitis B core antibody; HBeAb: Hepatitis B pre-core antibody; HBeAg: Hepatitis B pre-core antigen; HBsAb: Hepatitis B surface antibody; HBsAg: Hepatitis B surface antigen; HBV: Hepatitis B Virus; HIV: Human Immune Deficiency Virus; MEIA: Micro-particle Enzyme Immuno Assay; NOS: Newcastle-Ottawa Scale; QS: Quality assessment; RDT: Rapid diagnostic tests; REM: Random effect model; STls: Sexually transmitted infections; WHO: World Health Organization

\section{Supplementary Information}

The online version contains supplementary material available at https://doi. org/10.1186/s13690-021-00686-1.

Additional file 1: S1 Fig. A. Forest plot of sub-group analysis of HBV prevalence for Uganda. S2 Fig. B. Forest plot of sub-group analysis of HBV prevalence for Kenya. S3 Fig. C. Forest plot of sub-group analysis of HBV prevalence for Rwanda. S4 Fig. D. Forest plot of sub-group analysis of HBV prevalence for Tanzania.

Additional file 2: S5 Fig. E. Forest plot of sub-group analysis of HBA prevalence in articles published from 2016 to 2020. S6 Fig. F. Forest plot of sub-group analysis of HBV prevalence in articles published from 2011 to 2015. S7 Fig. G. Forest plot of sub-group analysis of HBV prevalence in articles published from 2005 to 2010.

Additional file 3: S8 Fig. H. Forest plot of sub-group analysis of $\mathrm{HBs} A g$ detection by ELISA assay. S9 Fig. I. Forest plot of sub-group analysis of HBsAg detection by rapid diagnostic test (RDT) assay. S10 Fig. J. Forest plot of sub-group analysis of HBsAg detection by Enzyme Immune Assay (EIA). S11 Fig. K. Forest plot of sub-group analysis of HBsAg detection by other assays.

Additional file 4: S 12 Table A. Detailed Newcastle-Ottawa Scale for each included study in the meta-analysis. 


\section{Acknowledgements}

We are grateful to ICT system management at Islamic University in UgandaKampala Campus for allowing us to access the data base. We also thank Dr. Ntanda K Moses, Makerere University College of Computing and Information Sciences for the ICT technical support.

\section{Authors' contributions}

HMK and HS conceived the idea. HMK, AW and AK participated in the search for the articles from the data bases. HMK and AW participated in the data presentation, analysis and discussion. HMK wrote the final manuscript draft. $\mathrm{PO}, \mathrm{ND}$ and $\mathrm{HK}$ reviewed the manuscript draft. All the authors read and approved the publication of the manuscript.

\section{Authors' information}

HMK is a molecular immunologist and virologist working on molecular immunology during hepatitis B virus infection targeting an African population. DN is an immunologist and biochemist with a PhD in Biochemistry and immunology working in the department of Plant Sciences, Microbiology and Biotechnology, College of Natural Sciences, Makerere University. HS holds a PhD in Biochemistry \& is a physician in the Department of Microbiology Makerere University working on molecular markers of drug resistance in HIV and malaria infections. PO is a physician with a PhD in gastroenterology and is an associate professor of gastroenterology with a lot of expertise in liver diseases working in the department of Medicine College of Health Sciences, Makerere University. AW is a microbiologist and immunologist working on anti-microbial resistance. AK is a physiologist working on anti-cancer drugs that can be used in the treatment of prostate carcinoma. HMK AK and AW are Ph.D. students at Makerere University in the colleges of Health Sciences and Natural Sciences employed at Islamic University in Uganda in the Departments of Medical Microbiology and Physiology as Doctoral fellows.

\section{Funding}

The authors declare that they did not receive any specific funding for the study.

\section{Availability of data and materials}

All data generated or analyzed during this study are included in this published article and as supplementary materials.

\section{Declarations}

Ethics approval and consent to participate

Not applicable.

\section{Consent for publication}

Not applicable.

\section{Competing interests}

The authors declare that they have no competing interests.

\section{Author details}

${ }^{1}$ Department of Medical Microbiology, Faculty of Health Sciences, Habib Medical School, Islamic University in Uganda, P.O. Box 7689, Kampala, Uganda. ${ }^{2}$ Department of Medical Microbiology, College of Health Sciences, Makerere University, P.O. Box 7062, Kampala, Uganda. ${ }^{3}$ Department of Plant Sciences, Microbiology and Biotechnology, College of Natural Sciences, Makerere University, P.O. Box 7062, Kampala, Uganda. ${ }^{4}$ Department of Medicine, College of Health Sciences, Makerere University, P.O. Box 7062, Kampala, Uganda. ${ }^{5}$ Department of Human Physiology, Faculty of Health Sciences, Habib Medical School, Islamic University in Uganda, P.O. Box 7689, Kampala, Uganda.

Received: 20 March 2021 Accepted: 2 September 2021 Published online: 18 September 2021

\section{References}

1. Matsuura MK, Tanaka Y, Hige S, Yamada G, Murawaki Y, Komatsu M, et al. Distribution of hepatitis B virus genotypes among patients with chronic infection in Japan shifting toward an increase of genotype A. J Clin Microbiol. 2009;47(5):1476-83. https://doi.org/10.1128/JCM.02081-08.
2. Nguyen VT, Law MG, Dore GJ. An enormous hepatitis B virus-related liver disease burden projected in Vietnam by 2025. Liver Int. 2008;28(4):525-31. https://doi.org/10.1111/j.1478-3231.2007.01646.x.

3. Weinbaum C, Williams I, Mast E, Wang S, Finelli L, Wasley A. Recommendations for identification and public health management of persons with chronic hepatitis B virus infection. MMWR Recomm Rep. 2008: $1-20$

4. WHO. Global Hepatitis Report; 2017. p. 0-80

5. Seremba E, Ssempijja V, Kalibbala S, Gray RH, Wawer MJ, Nalugoda F, et al. Hepatitis B incidence and prevention with antiretroviral therapy among HIVpositive individuals in Uganda. AIDS. 2017;31(6):781-6. https://doi.org/10.1 097/QAD.0000000000001399.

6. Ochola E, Ocama P, Orach CG, Nankinga ZK, Kalyango W, McFarland JN, et al. High burden of hepatitis B infection in Northern Uganda : results of a population-based survey. BMC Public Health. 2013;13(1):7. https://doi.org/1 0.1186/1471-2458-13-727.

7. Ramírez-Mena A, et al. Prevalence and outcomes of hepatitis B coinfection and associated liver disease among antiretroviral therapy-naive individuals in a rural Tanzanian human immunodeficiency virus cohort. Open Forum Infect Dis. 2016;3(3):ofw162.

8. Mirambo MM, et al. Prevalence of Hepatitis B surface antigen among pregnant women attending antenatal clinic at Nyamagana District Hospital Mwanza, Tanzania. Tanzan J Health Res. 2016;18(1).

9. Kwizera R, Moibéni A, Shenawy FY, Ussif M. The prevalence of hepatitis B and $\mathrm{C}$ among blood donors at the National Blood Transfusion Center (CNTS) in Burundi. Pan Afr Med J. 2018;31:119.

10. Kateera F, Walker TD, Mutesa L, Mutabazi C, Musabeyesu V, Mukabatsinda E, et al. Hepatitis B and C seroprevalence among health care workers in a tertiary hospital in Rwanda. Trans R Soc Trop Med Hyg. 2015;109(3):203-8. https://doi.org/10.1093/trstmh/trv004.

11. Kayondo SP, Byamugisha JK, Ntuyo P. Prevalence of hepatitis B virus infection and associated risk factors among pregnant women attending antenatal clinic in Mulago Hospital, Uganda: a cross-sectional study. BMJ Open. 2020;10(6):e033043.

12. Kafeero H, Ndagire D, Ocama P, Walusansa A, S. H. Sero-prevalence of human immunodeficiency virus-hepatitis B virus (HIV-HBV) co-infection among pregnant women attending antenatal care (ANC) in sub-Saharan Africa (SSA) and the associated risk factors: a systematic review and metaanalysis. Virol J. 2020;17(1):19

13. Rachel M, Barbara C, Murphy C, Komujuni C, Nyakato P, Ocama P, et al. Uptake of hepatitis B-HIV co-infection screening and management in a resource limited setting. Hepatol Med Policy. 2018;3(7):1-7. https://doi.org/1 $0.1186 / 541124-017-0030-3$

14. Frambo A, Atashili J, Fon P, Ndumbe P. Prevalence of HBsAg and knowledge about hepatitis B in pregnancy in the Buea Health District, Cameroon: a cross-sectional study. BMC Res Notes. 2014;7(1):394.

15. Bani l, et al. Prevalence and risk factors of hepatitis $B$ virus among pregnant women in Jazan region- Kingdom of Saudi Arabia. J Biol Agric Heal. 2012; 2(7):39-43.

16. Noubiap J, Nansseu J, Ndoula S, Bigna J, Jingi A, Fokom-Domgue J. Prevalence, infectivity and correlates of hepatitis B virus infection among pregnant women in a rural district of the Far North Region of Cameroon. BMC Public Health. 2015:15(1):454.

17. Eke A, Eke U, Okafor C, Ezebialu I, Ogbuagu C. Prevalence, correlates and pattern of hepatitis B surface antigen in a low resource setting. Virol J. 2011; 8:12.

18. Awole M, Gebre-Selassie S. Seroprevalence of HBsAg and its risk factors amoung pregnant women in Jimma, Southwest Ethiopia. Ethiop J Heal Dev. 2005;19(1):45-50. https://doi.org/10.4314/ejhd.v19i1.9970.

19. Mak D, Babb de Villiers C, Chasela C, Urban Ml, Kramvis A. Analysis of risk factors associated with hepatocellular carcinoma in black south Africans: 2000-2012. PLoS One. 2018;13(5):2000-12. https://doi.org/10.1371/journal. pone.0196057.

20. Lawal MA, Adeniyi OF, Akintan PE, Salako AO, Omotosho OS, Temiye EO. Prevalence of and risk factors for hepatitis B and C viral co-infections in HIV infected children in Lagos, Nigeria. PLoS One. 2020;15(12 December):1-15. https://doi.org/10.1371/journal.pone.0243656.

21. WHO. WHO Global health sector strategy on viral hepatitis 2016-2021. Geneva: Switz; 2016.

22. Page MJ, et al. The PRISMA 2020 statement : an updated guideline for reporting systematic reviews; 2021. p. 1-11. 
23. Stang A. Critical evaluation of the Newcastle-Ottawa scale for the assesment of the quality of non-randomised studies in meta-analysis of genome searches. Genet Epidemiol. 2010;25(9):603-5. https://doi.org/10.1007/s10654010-9491-z.

24. Begg CM. Operating characteristics of a rank correlation testfor publication bias. Biometrics. 1994;50(4):1088-101. https://doi.org/10.2307/2533446.

25. Zintzaras E. Heterogeneity testing in meta-analysis of genome searches. Genet Epidemiol. 2005;28(2):123-7. https://doi.org/10.1002/gepi.20048.

26. Mutagoma M, Balisanga $H$, Sebuhoro D, Mbituyumuremyi A, Remera E, Malamba SS, et al. Hepatitis B virus and HIV co-infection among pregnant women in Rwanda. BMC Infect Dis. 2017;17(1):1-7. https://doi.org/10.1186/ s12879-017-2269-0.

27. Hasegawa I, et al. Molecular epidemiology of hepatitis B virus in the United Republic of Tanzania. J Med Virol. 2006;78(8):1035-42.

28. Twagirumugabe $T$, et al. Hepatitis B virus strains from Rwandan blood donors are genetically similar and form one clade within subgenotype A1. BMC Infect Dis. 2017;17(1):32.

29. Bwogi J, Braka F, Makumbi I, Mishra V, Bakamutumaho B, Nanyunja M, et al. Hepatitis B infection is highly endemic in Uganda: findings from a national serosurvey. Afr Health Sci. 2009;9(2):98-108.

30. Matee MI, Magesa PM, Lyamuya EF. Seroprevalence of human immunodeficiency virus, hepatitis B and C viruses and syphilis infections among blood donors at the Muhimbili National Hospital in Dar Es Salaam, Tanzania. BMC Public Health. 2006;6(1):21.

31. Mueller CA, Stoetter L, Kalluvya S, Stich A, Majinge C, Weissbrich B, et al. Prevalence of hepatitis $B$ virus infection among health care workers in a tertiary hospital in Tanzania. BMC Infect Dis. 2015;15(1):1-9.

32. Bayo ADP, Ochola E, Oleo C, Mwaka. High prevalence of hepatitis B virus infection among pregnant women attending antenatal care: a crosssectional study in two hospitals in northern Uganda. BMJ Open. 2014;4(11): e005889.

33. Bongomin P, Magid K. Prevalence of hepatitis B virus (HBV) infection among Makerere University medical students. Afr Health Sci. 2005;5(2):93-8.

34. Harania RS, Karuru J, Nelson M, Stebbing J. HIV, hepatitis B and hepatitis C coinfection in Kenya. Aids. 2008;22(10):1221-2. https://doi.org/10.1097/QAD. ob013e32830162a8.

35. Iradukunda PG, Habyarimana T, Niyonzima FN, Uwitonze AY, Mpunga T. Risk factors associated with hepatitis B and C in rural population of Burera district, Rwanda. Pan Afr Med J. 2020;35:43.

36. Kirbak ALS. Sero-prevalence for Hepatitis B virus among pregnant women attending antenatal clinic in Juba Teaching Hospital, Republic of South Sudan. Pan Afr Med J. 2017;26:72.

37. Makuza JD, Rwema JOT, Ntihabose CK, Dushimiyimana D, Umutesi J, Nisingizwe $\mathrm{S}$, et al. Prevalence of hepatitis B surface antigen ( $\mathrm{HBsAg}$ ) positivity and its associated factors in Rwanda. BMC Infect Dis. 2019;19(1):381.

38. Muriuki BM, Gicheru MM, Wachira D, Nyamache AK, Khamadi SA. Prevalence of hepatitis B and C viral co-infections among HIV-1 infected individuals in Nairobi, Kenya. BMC Res Notes. 2013;6(1):33.

39. Ngaira JAM, Kimotho J, Mirigi I, Osman S. Prevalence, awareness and risk factors associated with Hepatitis B infection among pregnant women attending the antenatal clinic at Mbagathi District Hospital in Nairobi, Kenya. Pan Afr Med J. 2016;24:315.

40. Pirillo MF, Bassani L, Germinario EA, Mancini J, Vyankandondera MG, Okong $P$, et al. Seroprevalence of hepatitis $B$ and $C$ viruses among HIVinfectedpregnant women in Uganda and Rwanda. J Med Virol. 2007; 79(12):1797-801. https://doi.org/10.1002/jmv.21007.

41. Rusine J, et al. High seroprevalence of HBV and HCV infection in HIVinfected adults in Kigali, Rwanda. PLoS One. 2013;8(5):e63303.

42. Telatela SP, Matee MI, Munubhi EK. Seroprevalence of hepatitis B and C viral co-infections among children infected with human immunodeficiency virus attending the paediatric HIV care and treatment center at Muhimbili National Hospital in Dar-es-Salaam, Tanzania. BMC Public Health. 2007;7(1): 1-6. https://doi.org/10.1186/1471-2458-7-338.

43. Umutesi J, et al. Prevalence of hepatitis B and C infection in persons living with HIV enrolled in care in Rwanda. BMC Infect Dis. 2017;17(1):315.

44. Ziraba AK, Bwogi J, Namale A, Wainaina CW, Mayanja-Kizza H. Seroprevalence and risk factors for hepatitis B virus infection among health care workers in a tertiary hospital in Uganda. BMC Infect Dis. 2010;10:191.

45. Rashid S, Kilewo C, Aboud S. Seroprevalence of hepatitis B virus infection among antenatal clinic attendees at a tertiary hospital in Dar es Salaam, Tanzania. Tanzan J Health Res. 2014;16(1):9.
46. Bartonjo G, Oundo J. Prevalence and associated risk factors of transfusion transmissible infections among blood donors at Regional Blood Transfusion Center Nakuru and Tenwek Mission Hospital, Kenya. Pan Afr Med J. 2019;34:31.

47. Geffert K, et al. Prevalence of chronic HBV infection in pregnant woman attending antenatal care in a tertiary hospital in Mwanza, Tanzania: a crosssectional study. BMC Infect Dis. 2020;20(1):1-10.

48. Hawkins C, Christian B, Ye J, Nagu T, Aris E, Chalamilla G, et al. Prevalence of hepatitis $B$ co-infection and response to antiretroviral therapy among HIVinfected patients in Tanzania. Aids. 2013;27(6):919-27. https://doi.org/10.1 097/QAD.0b013e32835cb9c8.

49. Kamenya T, Damian DJ, Ngocho JS, Philemon RN, Mahande MJ, Msuya SE. The prevalence of hepatitis B virus among HIV-positive patients at Kilimanjaro Christian Medical Centre Referral Hospital, Northern Tanzania. Pan Afr Med J. 2017;28:275.

50. Kapinga DR. Seropevalence and factors associated with hepatitis $b$ virus infection in pregnant women attending antenatal clinic in Karagwe District Council, Kagera Region. Tanzan J Health Res. 2017;73:398.

51. Kilonzo SB, Gunda DW, Kashasha F, Mpondo BC. Liver fibrosis and hepatitis B coinfection among ART naive HIV-infected patients at a tertiary level hospital in northwestern Tanzania: a cross-sectional study. J Trop Med. 2017; 5629130.

52. Kerubo G, Khamadi S, Okoth V, Madise N, Ezeh A, Abdalla Z, et al. Hepatitis $B$, hepatitis $C$ and HIV-1 coinfection in two informal urban settlements in Nairobi, Kenya. PLoS One. 2015;10(6):e0129247.

53. Ng'wamkai G, et al. Treponema pallidum infection predicts sexually transmitted viral infections (hepatitis B virus, herpes simplex virus-2, and human immunodeficiency virus) among pregnant women from rural areas of Mwanza region, Tanzania. BMC Pregnancy Childbirth. 2019;19(1):392.

54. Shao ER, et al. Seroprevalence of hepatitis $B$ virus infection and associated factors among healthcare workers in northern Tanzania. BMC Infect Dis. 2018;18(1):474.

55. Chiesa A, Ochola E, Oreni L, Vassalini P, Rizzardini G, Galli M. Hepatitis B and HIV coinfection in Northern Uganda: Is a decline in HBV prevalence on the horizon? PLoS One. 2020;15(11):e0242278 https://doi.org/10.1371/journal. pone.0242278.

56. Meschi S, Schepisi MS, Nicastri E, Bevilacqua N, Castilletti C, Sciarrone MR, et al. The prevalence of antibodies to human herpesvirus 8 and hepatitis B virus in patients in two hospitals in Tanzania. J Med Virol. 2010;82(9):156975. https://doi.org/10.1002/jmv.21852.

57. Musa OL, B. M, Bussell S, Borodo MM, Samaila AA, Femi. Prevalence of hepatitis B virus infection in Nigeria, 2000-2013: a systematic review and meta-analysis. Niger J Clin Pract. 2015;18(2):163-72. https://doi.org/10.41 03/1119-3077.151035.

58. Ofori-Asenso R, Agyeman AA. Hepatitis B in Ghana: a systematic review \& meta-analysis of prevalence studies (1995-2015). BMC Infect Dis. 2016;16(1): 130.

59. Bigna JJ, Amougou MA, Asangbeh SL, Kenne AM, Noumegni SRN, NgoMalabo ET, et al. Seroprevalence of hepatitis B virus infection in Cameroon: a systematic review and meta-analysis. BMJ Open. 2017;7:e015298.

60. Lingani $M$, et al. High prevalence of hepatitis B infections in Burkina Faso (1996-2017): a systematic review with meta-analysis of epidemiological studies. BMC Public Health. 2018;18(1):551.

61. Badawi M, Atif M, Mustafa Y. Systematic review and meta-analysis of HIV, HBV and HCV infection prevalence in Sudan. Virol J. 15, 2018:148.

62. Hassan-Kadle PP, M. A, Osman MS, Ogurtsov. Epidemiology of viral hepatitis in Somalia: Systematic review and meta-analysis study. World J Gastroenterol. 2018;24(34):3927.

63. Schweitzer A, Horn J, Mikolajczyk R, Krause G, Ott J. Estimations of worldwide prevalence of chronic hepatitis $B$ virus infection: a systematic review of data published between 1965 and 2013. Lancet (London, England). 2015;386:1546-55.

64. Ntagirabiri R, Niyongabo T, Ndayiragije E, Baransaka. The prevalence of hepatitis B in Burundi national survey. Afr J Hepatol Gastroenterol. 2013;7(4): 199-2035. https://doi.org/10.1007/s12157-013-0495-7.

65. Yazie MG, T. D, Tebeje. An updated systematic review and meta-analysis of the prevalence of hepatitis B virus in Ethiopia. BMC Infect Dis. 2019;19(1):917.

66. Yun-Fan L, Chia-Ming C. Hepatitis B virus infection. Lancet. 2009;373(9663): 582-92.

67. Quadri NS, Shah SM, Rodin H, Debes JD. Promoting hepatitis B awareness: evaluating an educational approach through health care workers in Tanzania. Ann Glob Heal. 2021;87(1):1-6. https://doi.org/10.5334/aogh.3045. 
68. Shah SM, et al. Hepatitis B Awareness and Vaccination Patterns among Healthcare Workers in Africa. Am J Trop Med Hyg. 2020;103(6):2460-8. https://doi.org/10.4269/ajtmh.20-0521.

69. Awili H, Gitao G, Muchemi G. Seroprevalence and Risk Factors for Hepatitis $B$ Virus Infection in Adolescent Blood Donors within Selected Counties of Western Kenya. Biomed Res Int. 2020:1-6 https://doi.org/10.1155/2020/ 8578172.

70. Ott JJ, Horn J, Krause GA, Mikolajczyk RT. Time trends of chronic HBV infection over prior decades-a global analysis. J Hepatol. 2017;66(1):48-54. https://doi.org/10.1016/j.jhep.2016.08.013.

71. Baseke J, Musenero M, Mayanja-Kizza H. Prevalence of hepatitis B and C and relationship to liver damage in HIV infected patients attending Joint Clinical Research Centre Clinic (JCRC), Kampala, Uganda. Afr Health Sci. 2015;15(2): 322-7. https://doi.org/10.4314/ahs.v15i2.3.

72. $\mathrm{MOH}$. Ministry of Health Uganda, 2015 Press statement on the World Hepatitis Day By the Ministry of Health Ugandan Government. Ps@health. go.ug. 2015.

73. Man-Fung Y, Ching-Lung L. Treatment of chronic hepatitis B: evolution over two decades. J Gastroenterol Hepatol. 2011;26(Suppl. 1):138-43.

74. Mutocheluh M, Owusu M, Kwofie T, Akadigo T, Appau E, Narkwa P. Risk factors associated with hepatitis B exposure and the reliability of five rapid kits commonly used for screening blood donors in Ghana. BMC Res Notes. 2014;7:873.

75. WHO. World Health Organization. World Health Assembly approves resolution on hepatitis and mechanism to coordinate non-communicable disease response. (2014). 2014. http://www.who.int/mediacentre/news/relea ses/2014/.

76. Amidu N, Owiredu W, Addai-Mensah O, Alhassan A, Quaye L, Batong B. Seroprevalence and risk factors for human immunodeficiency virus, hepatitis $B$ and $C$ Vi-ruses infections among blood donors at the Bolgatanga Regional Hospital in Bolgatanga, Ghana. J Ghana Sci Assoc. 2010;12(1).

77. Omatola CA, Onoja BA, Agama J. Detection of hepatitis B surface antigen among febrile patients in Ankpa, Kogi State, Nigeria. J Trop Med. 2020; 5136785.

78. Martinson FE, Weigle KA, Royce RA, Weber DJ, Suchindran CM, Lemon SM. Risk factors for horizontal transmission of hepatitis B virus in a rural district in Ghana. Am J Epidemiol. 1998;147(5):478-87. https://doi.org/10.1093/ oxfordjournals.aje.a009474.

79. C. . A. Anaedobe, C. Fowotade, Omoruyi, and R. Bakare, "'Prevalence, sociodemographic features and risk factors of hepatitis B virus infection among pregnant women in Southwestern Nigeria," Pan Afr Med J, vol. 20, pp. 1-11, 2015, DOl: https://doi.org/10.11604/pamj.2015.20.406.6206.

80. Samal N, Padhi S, Burman L. Seroprevalence of hepatitis B infection among pregnant women in Southern Odisha. Indian J Med Spec. 2019;10(4):207.

81. EL-Gasim RA, Eltayeb N, Khidir I. Hepatitis B virus infection in pregnant women, in Al Fashir Town, North Darfur State, Sudan. Open J Med Microbiol. 2019;9(1):28-36.

82. Desalegn YAE, Wassie ZL, Beyene HB, Mihret A. Hepatitis B and human immunodeficiency virus coinfection among pregnant women in resourcelimited high endemic setting, Addis Ababa, Ethiopia: implications for prevention and control measures. Eur J Med Res. 2016;21(1):1-7. https://doi. org/10.1186/s40001-016-0211-3.

83. Andersson MI, Maponga TG, ljaz S, Barnes J, Theron GB, Meredith SA, et al. The epidemiology of hepatitis B virus infection in HIV-infected and HIVuninfected pregnant women in the Western Cape, South Africa. Vaccine. 2013;31(47):5579-84. https://doi.org/10.1016/j.vaccine.2013.08.028.

84. Ezechi OC, et al. Sero-prevalence and factors associated with Hepatitis B and C co-infection in pregnant Nigerian women living with HIV Infection. Pan Afr Med J. 2014;17(1):197.

85. Dionne-Odom J, et al. Hepatitis B, HIV, and syphilis seroprevalence in pregnant women and blood donors in Cameroon. Infect Dis Obstet Gynecol. 2016;4359401.

86. Landes M, Tibaldi C, Newell ML, Barlow P, Fiore S, Malyuta R, et al. Hepatitis B or hepatitis C co-infection in HIV-infected pregnant women in Europe. HIV Med. 2008;9(7):526-34. https://doi.org/10.1111/j.1468-1293.2008.00599.x.

87. Mave TCV, Kadam D, Kinikar A, Gupte N, Bhattacharya D, Bharadwi R. Impact of maternal hepatitis B virus co-infection on mother-to-child transmission of HIV. HIV Med. 2014;15(6):347-54. https://doi.org/10.1111/hiv.12120.

88. Matthews PC, Geretti AM, Goulder PJ, Klenerman P. Epidemiology and impact of HIV coinfection with hepatitis B and hepatitis $C$ viruses in sub-
Saharan Africa. J Clin Virol. 2014;61(1):20-33. https://doi.org/10.1016/j.jcv.2 014.05.018.

89. Mukasa KH, Abubaker K, Mariam N, Saad A. The S-gene mutations in the circulating HBV genotypes / sub- genotypes associated with hepatitis B infection in Uganda and their effects on cytokines expression in liver disease progression. Section one : Background. 2021;02(03):162-74.

90. Kafeero M, Sendagire H, Ocama P, Ndagire D. Host and viral factors associated with hepatitis B clinical outcomes in chronic infection-review article. Int J Pure Med Res. 2019;4(3):9-15.

91. Kafeero HM, Ndagire D, Nanyingi $H$, Sendagire $H$. Host genetic factors associated with hepatitis B virus infection and progression to chronic disease: A systematic review and Meta analysis, y (Preprint). BMC Immunol. 2019. https://doi.org/10.21203/rs.2.12164/v1.

\section{Publisher's Note}

Springer Nature remains neutral with regard to jurisdictional claims in published maps and institutional affiliations.
Ready to submit your research? Choose BMC and benefit from:

- fast, convenient online submission

- thorough peer review by experienced researchers in your field

- rapid publication on acceptance

- support for research data, including large and complex data types

- gold Open Access which fosters wider collaboration and increased citations

- maximum visibility for your research: over $100 \mathrm{M}$ website views per year

At BMC, research is always in progress.

Learn more biomedcentral.com/submissions 